\title{
Antonia Jenik*
}

\section{Martyrium oder Askese?}

\section{Felix und Maximus im 4. Natalicium $(=\text { carm. } 15)^{1}$ des Paulinus von Nola}

DOI 10.1515/phil-2016-0005

\begin{abstract}
Paulinus of Nola developed in his fourth Natalicium a contemporary concept of holiness, from the representation and interaction of the two protagonists Felix and Maximus. In place of martyrdom, he placed at the centre of the work a form of 'alternative martyrdom', e.g. asceticism or service to people. The two main characters Felix and Maximus are initially portrayed as two different types and represent two entirely different ideals: the presbyter Felix represents, as a perfect saint-template, the Martyr-Ideal, while the Bishop Maximus embodies asceticism as a weak human. In the course of the action, through acquaintance with the suffering Bishop Maximus, Felix transforms himself from a rigorous and superhuman martyr to a human and philanthropic patron and helper of the needy. This coincides with a gradual replacement of the Martyr-Ideal with the Ideal of an 'alternative martyrdom' (e.g. asceticism), which is elevated to an equal norm of holiness and increasingly attains importance. Paulinus manages, through different narrative strategies, to embed the fourth Natalicium in the contemporary religious, cultural, and literary movements, and at the same time to design an entirely original and innovative profile and concept for St. Felix.
\end{abstract}

Keywords: Hl. Felix von Nola, Bischof Maximus, Martyrium, Askese, Konzeption von Heiligkeit

Wenn das kein Skandal, keine Ohrfeige für die ,echten‘ Märtyrer ist! Da wird der heilige Felix von Nola in zwei Christenverfolgungen mehrfach durch göttliches Eingreifen vor dem drohenden Martyrium bewahrt und erhält trotzdem den Ehrentitel ,Märtyrer‘ (Paul. Nol. carm. 15,46), obwohl er doch streng genommen

1 Nummerierung und Zitierung der Carmina erfolgen nach von Hartel/Kamptner ( $\left.{ }^{2} 1999\right)$.

*Kontaktperson: Antonia Jenik, Ludwig-Maximilians-Universität München, Abteilung für Griechische und Lateinische Philologie, Geschwister-Scholl-Platz 1, 80539 München, E-Mail: a.jenik@gmx.de 
bloß als confessor gelten dürfte. Doch damit nicht genug. Denn der Vorgesetzte des Felix, der Bischof Maximus, flieht beim Ausbruch der Verfolgung in die Wildnis und wird dennoch als confessor tituliert (v. 230; v. 339), ja mehr noch: Die Unannehmlichkeiten, die er in der Einöde erdulden muss, werden als eine Art von Martyrium angesehen (diversa at non leviore ferebat / martyrium cruce, vv. 200f.).

Wenn ein confessor zum Märtyrer, ein Flüchtling zum confessor und ein Leben auf der Flucht zum Martyrium stilisiert werden können - welche Konzeption von confessio bzw. Martyrium liegen dieser befremdlichen Darstellung zugrunde? Welche Wertschätzung wird jeweils den unterschiedlichen Handlungen und Haltungen der Protagonisten gezollt? Und welche Konsequenzen ergeben sich daraus für die Definition von Heiligkeit?

Derartige Fragen werfen sich auf, wenn man die Lebensbeschreibung des hl. Felix von Nola ${ }^{2}$ liest, die Paulinus von Nola ${ }^{3}$ zwischen 398 und 400 n. Chr. ${ }^{4}$ verfasst hat. Diese Biographie ${ }^{5}$ nimmt unter all den Heiligenbiographien, die zur Zeit des Paulinus kursierten (Vita Cypriani des Pontius; Vita Antonii des Athanasius, Vita Pauli; Vita Malchi und Vita Hilarionis des Hieronymus; Vita Martini des Sulpicius Severus) eine Sonderstellung ein. ${ }^{6}$ Das zeigt sich auch schon an ihrer formalen Gestaltung, die in drei Punkten vom gängigen Modell einer Heiligenvita

2 Zum Heiligenkult allgemein, aber mit Bezugnahme auf Paulinus und Felix von Nola vgl. Brown (1981). Felix von Nola lässt sich zeitlich nur ungefähr verorten, etwa um 250 oder $300 \mathrm{n}$. Chr. (Walsh 1975, 9f.; Prete 1983, 151 f.; Evenepoel 1991, 143f.; Luongo 1992, 20 f.; Seng 2006, 483).

3 Zu Paulinus von Nola vgl. Fabre (1949); Lienhard (1977); Trout (1990, 1999) und Mratschek (2002).

4 Datierung nach Fabre (1948) 113-115, 138f. Ihm folgen Walsh (1975) 6f., Prete (1983) 151, Evenepoel (1989) 167 f. sowie (1991) 143 und Luongo (1992) 35-38. Dagegen setzt Desmulliez (1985) 59-61; 63 die Jahre 397-399 n. Chr. als Entstehungszeit an.

5 Dieser Text wird in der Forschung - allerdings ohne nähere Begründung - mit verschiedensten literarischen Gattungsbezeichnungen belegt: „Vita Felicis“ (Evenepoel 1989 und 1991, jeweils bereits im Titel; Luongo 1992, 35; Kirsch 2004, 26; 88; Sciajno 2008, 30), „passio poetica“ (Prete 1983, 150) und „actus S. Felicis“ (Prete 1983, 151) sowie „epopea“ (Luongo 1992, 35), „epica cristiana“ (Ruggiero 1996, 74) und „हैंToৎ cristiano“ (Sciajno 2008, 30). Da diese teils sehr speziellen und nicht unproblematischen Gattungszuordnungen hier nicht untersucht werden können, werden im Folgenden allein die Begriffe ,Natalicium', ,Gedicht‘ und ,Biographie“ verwendet, die breite Anerkennung gefunden haben und/oder einen möglichst weit gesteckten Rahmen bieten.

6 Prete (1983) 152 bezeichnet sie als „una pièce agiografica eccezionale“. Diese Sonderstellung mag der Grund dafür sein, dass die Felix-Biographie kaum als ,echte' Heiligenbiographie wahrgenommen wird. 
abweicht: Der Versform (Hexameter) ${ }^{7}$, der Einbettung in ein Natalicium $^{8}$ und der Konzeption als Fortsetzungsgeschichte. ${ }^{9}$

Dass sich hinter dieser innovativen Form ein ebenso ungewöhnlicher Inhalt verbirgt, nämlich eine ganz spezielle Konzeption von Märtyrertum und christlicher Vervollkommnung sowie vom besonderen Wesen und Wirken des Heiligen, ist bereits zu Beginn angeklungen und wird im Folgenden ausführlich dargelegt. In diesem Sinne soll dieser Beitrag zeigen, dass

1. im 4. Natalicium zwei Protagonisten (Felix und Maximus) auftreten, die zwei konträre Typen (Heiliger und Mensch) verkörpern und zwei verschiedene Formen christlicher Perfektion (Martyrium und Askese) vertreten,

2. Felix in der Interaktion mit und unter dem Einfluss von Maximus eine tief greifende Verwandlung durchläuft,

7 Damit stellt die Felix-Biographie nicht nur die erste Versbiographie der lateinischen Hagiographie dar (Fabre 1949, 364; Prete 1983, 150; Luongo 1992, 16), sondern ist schon durch ihre äußere Form als christliches Pendant zum traditionellen Epos gekennzeichnet.

8 Die Natalicia sind allerdings keine Genethliaka im klassischen Sinne, denn konventionelle Gattungselemente werden christlich umgeformt: So richtet sich der Lobpreis nicht an einen Lebenden, sondern einen Toten, und es wird nicht der Geburtstag, sondern der Todestag des Adressaten begangen (Ruggiero 1996, 25; Kirsch 2004, 81; Sciajno 2008, 23f.); nach christlicher Tradition stellt nämlich der Tod die Geburt zum ewigen Leben und der Todestag entsprechend den Geburtstag für den Himmel dar (Fabre 1949, 339; Walsh 1975, 7; Brown 1981, 57; Kirsch 1983, 333 und 2004, 21; Burkhard 1991, 154-156; Angenendt 1994, 129; Ruggiero 1996, 25; Seng 2006, 483; Sciajno 2008, 21; 61f. zu v. 2; Kleinschmidt 2013, 119). Zudem integrieren die Natalicia eine Vielzahl von Charakteristika weiterer literarischer Formen, wie z. B. Hagiographie, Epik, Bukolik, Gebet etc. Damit spiegeln sie die spätantike Tendenz zur Mischung und Umdeutung der literarischen Gattungen (vgl. Herzog 1977).

9 Wie viele Gedichte zur Biographie gerechnet werden, variiert je nach dem zugrunde gelegten biographischen Konzept. Stellt man das irdische Leben und Wirken des Felix in den Vordergrund, dann besteht die Biographie aus zwei Teilen, dem 4. und 5. Natalicium (= carm. 15 und 16) (Fabre 1949, 349; 364; Walsh 1975, 8; Prete 1983, 149f.; Evenepoel 1989 und 1991; Luongo 1992, 16; Ruggiero 1996, 26f.; Skeb 1997, 270; Seng 2006, 483; Sciajno 2008, 34). Berücksichtigt man dagegen, dass nach christlichem Verständnis der Tod ein elementarer Bestandteil im Leben des Heiligen und damit auch in seiner Lebensbeschreibung ist, so muss man noch das 6. Natalicium (= carm. 18) miteinbeziehen (Trout 1990, 116; Kirsch 2004, 26; 77; 88-91 und Kleinschmidt 2013, 120). Dies ist insofern naheliegend und sinnvoll, als Paulinus selbst die drei Natalicia durch explizite Rückbezüge auf das/die vorhergehende(n) Gedicht(e) zu einer Einheit verbunden hat: So verweist er in carm. 16,17 durch liber auf das 4. Natalicium und in carm. 18,70 durch libellis auf das 4. sowie das 5. Natalicium. Demnach setzt sich die Biographie aus drei Teilen zusammen: Während das 4. und 5. Natalicium das irdische Leben des Felix schildern, beschreibt das 6 . Natalicium seinen Tod, seine Aufnahme in den Himmel und das erste Wunder an seinem Grab. Somit ist das 6. Natalicium zwar noch Teil der Biographie, fungiert aber zugleich als Bindeglied und Übergang zu den folgenden Natalicia, in denen die postmortale Wundertätigkeit des Heiligen thematisiert wird. 
3. im Verlauf der Erzählung die beiden Formen christlicher Perfektion (Martyrium und Askese) bewertet, verglichen und in einen engen Zusammenhang gebracht werden,

4. Felix letztendlich als, moderner' Heiliger mit einem besonderen Profil etabliert wird.

Mit diesen Ansätzen lassen sich auch einige der Fragen bzw. Probleme klären, die sich in den Studien von Luongo (1992), Basson (2003) und Seng (2006) über das Heiligenkonzept des Felix ergeben und hier kurz skizziert werden sollen.

Die ausführlichste Untersuchung stammt von Luongo (1992). Er sieht in der Figur des Felix vier ${ }^{10}$ Ideale bzw. Rollen vereint: Märtyer/confessor ${ }^{11}$, pastor $^{12}$, sacerdos ${ }^{13}$ und Mönch ${ }^{14}$. Im Zentrum der Darstellung stehe dabei die „pastoralità“;15 eine nähere Beziehung zwischen den Einzelidealen lasse sich aber kaum herstellen. ${ }^{16}$

Eine solche Beziehung ist jedoch von immenser Wichtigkeit, denn die vier Ideale sind so vielseitig und zugleich so widersprüchlich, dass sie kaum von einer einzigen Person zur gleichen Zeit und in gleicher Intensität vertreten werden können. Zwar lassen sich die Rollen ,pastor', ,sacerdos` und ,Mönch“ nach dem Beispiel des Mönchsbischofs Martin von Tours noch miteinander in Einklang bringen; doch die Rolle des Märtyrers kann allein dann mit den drei anderen Rollen vereinbart werden, wenn das Martyrium erst nach der Betätigung als Priester oder Mönch erfolgt und somit die letzte Episode und Krönung des Lebens darstellt ${ }^{17}$ - aber das ist in der Felix-Biographie dezidiert nicht der Fall.

Zudem geht Luongo auf die Figur des Maximus kaum ein, obwohl die Beschreibung seiner Situation sowie seiner Handlungen und Emotionen an Ausführlichkeit und Detailtreue den Schilderungen über Felix kaum nachsteht. Das ist

10 Evenepoel (1991) 151 geht wie Kirsch (2004) 18f. nur von zwei Rollen aus: confessor/Märtyrer und Asket.

11 Luongo (1992) 63-69.

12 Luongo (1992) 70-74 mit Verweis auf Parallelen zu Cyprian und Polycarp.

13 Luongo (1992) $75-87$.

14 Luongo (1992) 87-90 mit Verweis auf Parallelen zu Antonius, Martin von Tours und Johannes dem Täufer.

15 Luongo (1992) 94. Genau gegensätzlich Seng (2006) 488, der das Märtyrertum im Vordergrund sieht.

16 Luongo (1992) 94.

17 So in der Vita Cypriani des Pontius, in der das Martyrium auf die Bischofstätigkeit folgt. In der Vita Antonii und den Mönchsviten des Hieronymus wird das Märtyrer-Ideal nur kurz am Rande behandelt (Ath. v. Anton. 46, 1-7; Hier. vita Pauli 2-5); so auch Evenepoel (1991) 151 Anm. 18 über die Vita Antonii. 
umso erstaunlicher und auffälliger, als alle übrigen Figuren in den beiden Natalicia (Vater und Bruder des Felix sowie die Haushälterin des Maximus im 4. Natalicium; die Verfolger, die Frau bei der Zisterne, Archelais und Quintus im 5. Natalicium) lediglich im Hintergrund erscheinen, ja zum Teil sogar komplett anonym bleiben. ${ }^{18}$ Maximus wird folglich von den übrigen Handelnden stark abgesetzt und in die Nähe des Felix gerückt. Doch warum erhält er diesen Sonderstatus? Welche Bedeutung hat Maximus für Felix und für das von ihm vertretene Heiligenkonzept? Und wie ist auf diesem Hintergrund dann mit seiner Flucht umzugehen, die - zumindest innerhalb des 4. Natalicium - in völligem Kontrast zum Verhalten des Felix steht?

Im Gegensatz zu Luongo nimmt Basson (2003) die Figur des Maximus in den Blick, jedoch in nicht unproblematischer Weise. Denn er sieht Maximus als Gegenüber des Felix in einem Vergleich, der darauf abziele, die Überlegenheit der modernen, urbanen Askese gegenüber der traditionellen Wüsten-Askese zu beweisen und damit das herrschende Vorurteil gegen Mönchsbischöfe abzubauen. ${ }^{19}$

Wenn jedoch, wie Basson vorschlägt, die Felix-Biographie das Ideal des Mönchsbischofs propagieren soll, ${ }^{20}$ dann müsste zumindest eine der (Haupt-) Figuren als ein solcher dargestellt sein, d.h. die beiden Rollen ,Mönch“ und ,Bischof' gleichzeitig ${ }^{21}$ ausüben. Davon ist jedoch nirgendwo die Rede: Denn als Felix zum Asketen wird (carm. 16,284-296), hat er die Ernennung zum Bischof bereits abgelehnt (vv. 229-239). Und in der Zeit, als Maximus in der Wildnis ein asketisches Leben führt (carm. 15,198-219), wird sein Bischofsamt komplett ausgeblendet, aber nicht deshalb, weil es mit der Askese nicht vereinbar wäre oder zu ihren Gunsten vernachlässigt würde, sondern aus dem einfachen Grund, dass es während der Flucht keine Rolle spielt.

Wenn Basson weiterhin den Vergleich zwischen Felix und Maximus als einen Vergleich zwischen dem alten und dem neuen Mönchs-Ideal sieht, ${ }^{22}$ so ist damit implizit jedem der beiden Protagonisten lediglich ein einziges der zwei Ideale zugewiesen. Das greift jedoch für Felix zu kurz, denn er lebt nicht nur als ,moderner‘ Mönch in der Gemeinde (carm. 16,284-296), sondern auch während

18 Für sie trifft die Feststellung von Kirsch (2004) 11 zu, dass in Heiligenbiographien alle anderen Personen „als nebensächliche zeitweilige Begleiter und Kontrastfiguren oder Objekte der Wundertätigkeit“ hinter den Heiligen zurücktreten. Für Maximus dagegen gilt dies nur zum Teil: Zwar vereint er all diese drei Funktionen (Begleiter, Kontrastfigur, Objekt der Wundertätigkeit) in sich, doch er tritt nur scheinbar hinter den Heiligen zurück.

19 Basson (2003) 133; 147-149.

20 Basson (2003) 148.

21 So in der Vita Martini des Sulpicius Severus. Zu Mönchsbischöfen und der daraus resultierenden Verbindung von ,ascetic authority“ mit „pragmatic authority“ vgl. Rapp (2005) 137-152.

22 Basson (2003) $147 \mathrm{f}$. 
der zweiten Verfolgung als eine Art Einsiedler abseits der Stadt (procul ... devius, v. 85; in regione remota, v. 155). So vertritt er beide Ideale in einer Person und darf nicht für die gesamte Erzählung als Vertreter der neuen Form in einen Gegensatz zu Maximus gebracht werden.

Zudem ist Bassons Annahme, die von Maximus vertretene ,alte' Form der Askese müsse durch sein Scheitern als überholt gelten, ${ }^{23}$ vor dem Hintergrund des 5. Natalicium zurückzuweisen. Denn dort führt Felix in der Zisterne ein recht ähnliches Einsiedlerdasein (vv. 155-214) - und das durchaus erfolgreich. Die Ursache für das Versagen liegt demnach offensichtlich in der Person des Asketen begründet, nicht aber in der Art der Askese an und für sich, die daher auch nicht durch eben diese Episode als obsolet erwiesen wird.

Schließlich wird Bassons Interpretation, die Maximus lediglich als (gescheiterten) Vertreter des traditionellen Askese-Konzepts und als zweitrangigen Vergleichspartner des Felix betrachtet, ${ }^{24}$ nicht allen Dimensionen dieser Figur gerecht. Denn zum einen übernimmt der Bischof am Ende des 4. Natalicium (carm. 15,354-361) mit der Segnung des Felix eine aktive und unverzichtbare Rolle; zum anderen ist nicht allein Maximus auf eine Beziehung zu Felix hin angelegt, sondern das gilt umgekehrt in gleicher Weise.

Seng (2006) befasst sich in seiner Studie mit dem Paradoxon, dass Felix als Märtyrer gefeiert wird, ohne ein Martyrium erlitten zu haben. Das Martyrium sei folglich als eine „Norm der Heiligkeit“25 aufgefasst, deren Erfüllung jedoch „,wenigstens im Ausnahmefall ... auch in anderer Weise als der ,normalen' möglich ist“"26. Eine solch symbolische Erfüllung leiste Felix durch seine bloße Bereitschaft zum Martyrium einerseits sowie seinen Kampf gegen die Dämonen andererseits.

Wenn Seng das symbolische Martyrium als Ausnahme einstuft, ${ }^{27}$ so trifft diese Aussage zwar zu, doch nur für die Zeit der Christenverfolgung, in der Felix lebt. In dieser Epoche war das echte Martyrium die vorherrschende Norm der Heiligkeit; das symbolische Martyrium dürfte dagegen als eine - wohl eher unrühmliche - Abweichung vom herkömmlichen Standard gegolten haben. In der Zeit des Paulinus dagegen hat sich die Praxis des ,Ersatzmartyriums` bereits gegen das tatsächliche Martyrium durchgesetzt und der ehemalige Sonderfall ist zur Regel geworden, wie die zeitgenössischen Mönchsviten beweisen. Die Bewertung des (symbolischen) Martyriums ist also von den Gegebenheiten der jeweiligen Epoche abhängig und damit einem grundlegenden Wandel unterzogen.

23 Basson (2003) 149.

24 Basson (2003) 133; 136; 149.

25 Seng (2006) 485.

26 Seng (2006) 484.

27 Seng (2006) 484. 
Dieser Wandel wird jedoch nur dann sichtbar, wenn die zwei verschiedenen Zeiträume, in denen der hl. Felix einerseits und Paulinus andererseits leben, präzise voneinander getrennt sind.

Weiterhin bewertet Seng zwar zu Recht die Bereitschaft zum Martyrium als eine symbolische Erfüllung der Märtyrernorm, ${ }^{28}$ doch er geht an keiner Stelle darauf ein, dass diese Bereitschaft bei Felix massiv abnimmt, wie seine diametral entgegengesetzten Verhaltensweisen in den beiden Christenverfolgungen nahelegen: Während sich Felix in der ersten Verfolgung (carm. 15,114-197) geradezu nach dem Martyrium sehnt und sich daher regelrecht als Zielscheibe für die Verfolger exponiert (vv. 126-128; vv. 167-178), flieht er bei der zweiten Verfolgung (carm. 16,52-214) aus der Stadt (vv. 82-90; vv. 149-157) und hält sich sechs Monate lang verborgen (vv. 192-196). Was hat sich in der Zwischenzeit zugetragen, das diese völlige Verkehrung der Einstellungen und Handlungen des Heiligen erklären könnte? Warum ist der Felix im 5. Natalicium nicht mehr derselbe wie im 4. Natalicium? Und wie kann dann die Märtyrernorm (symbolisch) erfüllt werden, wenn die Bereitschaft zum Martyrium nicht mehr besteht?

Dass Seng schließlich den Dämonenkampf des Felix als symbolisches Martyrium deutet, ${ }^{29}$ ist insofern problematisch, als damit zwei inhaltlich und zeitlich getrennte und gegensätzliche Ebenen miteinander vermischt werden: Immerhin wird ein Martyrium gewöhnlich im Diesseits durchlitten und als außerordentliches Verdienst angerechnet, das dem Märtyrer im Jenseits einen besonderen Lohn einbringt; der Kampf des Felix gegen die Dämonen spielt sich jedoch erst nach dem Tod des Heiligen ab. Die Befähigung zu diesem Kampf ist demnach nicht ein Verdienst, das sich Felix im irdischen Leben errungen hat, sondern ein himmlischer Lohn, den er in seiner postmortalen Existenz für (ein) vorhergehende(s), noch zu Lebzeiten erworbene(s) Verdienst(e) empfängt. ${ }^{30}$ Lediglich solche auf Erden vollbrachten Verdienste können als weitere Ausprägung eines symbolischen Martyriums und als gleichwertiger Ersatz für die Bereitschaft zum Martyrium angesehen werden. ${ }^{31}$

Diese Schwierigkeiten und offenen Fragen zeigen, dass das von Luongo, Basson und Seng vorgestellte Heiligenkonzept für Felix noch modifiziert und erweitert werden sollte. $\mathrm{Zu}$ diesem Zweck wird nun beleuchtet, wie die Figuren

28 Seng (2006) 485.

29 Seng (2006) $485 \mathrm{f}$.

30 Ebenso Skeb (1997) 276.

31 Skeb (1997) 272 sieht den Kampf gegen die Laster als Martyrium (276). Dafür bietet der Text jedoch keine Grundlage, denn der Kampf und Sieg gegen die Laster sind als „proelia“ (carm. 16,247 ) und „ali $[a]$... palm $[a]$ “ (v. 255) präsentiert, aber nicht mit einem Begriff aus dem Wortfeld ,Martyrium/Märtyrer‘ verbunden. 
Felix und Maximus gezeichnet sind und mit welchen erzähltechnischen Mitteln die Darstellung gestaltet bzw. verstärkt wird. Diese Analyse stützt sich auf Textpassagen, in denen die Taten und Worte, Gedanken und Gefühle, Einstellungen und Verhaltensweisen der Protagonisten sowohl in ihrem eigenständigen, isolierten Agieren als auch in ihrer Interaktion detailliert beschrieben werden. Textpassagen solcher Art finden sich lediglich in einem kleinen Ausschnitt der Felix-Biographie, nämlich allein im 4. Natalicium, ${ }^{32}$ und auch dort ausschließlich in seinem zweiten Teil $^{33}$ (carm. 15,114-361), d.h. im Bericht über die Verfolgungszeit. Dieser Bericht macht mit 248 Versen ca. zwei Drittel des 4. Natalicium aus und ist damit bereits durch seinen Umfang als Hauptteil gekennzeichnet. Zudem hebt er sich durch seine besondere Figurenkonstellation wie auch durch den verstärkten Einsatz von erzählerischen Mitteln und Techniken auffällig vom Rest des Gedichts ab.

So wird erst in der Episode über die Verfolgung die zweite Hauptfigur, Bischof Maximus, ins Geschehen eingeführt. Die Vorstellung seiner Person unterscheidet sich fundamental von der des Felix, denn sie beschränkt sich auf die notwendigsten Angaben zum Verständnis der folgenden Ereignisse. In bunter Abfolge werden Informationen unterschiedlichster Art auf weniger als fünf Verse (vv. 120124) zusammengedrängt, wobei die Ausführlichkeit und Präzision der Einzelangaben beträchtlich voneinander abweichen. So erwähnen die ersten beiden Verse (vv. 120 f.) recht knapp und allgemein sowie ohne erkennbaren logischen Zusammenhang das Alter (senior, v. 120; durch die Position am Versbeginn als besonders wichtig markiert), die Funktion (sanctis ... legibus ... / ... formabat, v. 120 f.), die Gemeinde (Nolanam ... urbem, v. 120), den Charakter (placido ... ore, v. 121) und den kirchlichen Rang (episcopus, v. 121) des Maximus. Die folgenden zwei Verse (vv. 122-124) widmen sich dagegen ausführlich nur einem einzigen Thema: Der Verbindung des Maximus zu Felix. Maximus sieht in Felix einen Helfer (v. 122), einen potentiellen Amtsnachfolger (v. 123f.) und sogar eine Art ,Ersatzsohn‘ (v. 122f.). Die Beschreibung des Maximus konzentriert sich somit sehr stark auf seine Beziehung zu Felix; die zweite Figur im Gedicht wird demnach zumindest teilweise nicht für sich wahrgenommen, sondern über und durch den Protagonisten definiert. Das erweckt den Anschein, als spiele Maximus eine

32 Im 5. Natalicium wird Maximus bloß zwei Mal erwähnt: Zu Beginn des Gedichts in der Zusammenfassung der bisherigen Ereignisse (carm. 16,27-33) und später bei der lapidaren Erwähnung seines Todes (vv. 229f.). Die Funktion des Maximus beschränkt sich folglich darauf, die Erinnerung des Publikums ,aufzufrischen' und eine weitere Großtat des Felix, nämlich die Ablehnung des Bischofsamtes, auszulösen. Bedeutung und Präsenz des Maximus sind hier also auf ein Minimum reduziert, sodass das 5. Natalicium im Rahmen der angestrebten Untersuchung allenfalls für einen Ausblick in die ,Zukunft‘ des Felix herangezogen werden kann.

33 Vgl. die Gliederung bei Evenepoel (1991) 144-146. 
unbedeutende Nebenrolle, und dieser Eindruck wird noch dadurch verstärkt, dass der erste Auftritt des Bischofs in die Felix-Handlung eingeschoben ist und darin lediglich ein kurzes Intermezzo darstellt. Maximus betritt die Bühne, um gleich darauf wieder abzugehen und für 72 Verse komplett von der Bildfläche zu verschwinden.

Diese Figurenkonstellation hat zur Folge, dass sich mit der Flucht des Maximus die Handlung in zwei Erzählstränge aufspaltet, denn nur so können die verschiedenen Ereignisse geschildert werden, die Maximus und Felix zeitgleich, aber voneinander getrennt an unterschiedlichen Orten erleben. Der erste Erzählstrang zeigt die Kerkerhaft des Felix (vv. 126-137 bzw. 164-197), der zweite den Aufenthalt des Maximus in der Wildnis (vv. 198-229), wobei diese Episode durch das Wort interea (v. 198) am Beginn des Erzählblocks als Parallelgeschehen zur Felix-Handlung gekennzeichnet ist. Beide Erzählstränge sind rhetorisch wie auch dramatisch stark aufgeladen und stehen damit in deutlichem Kontrast zum ersten Drittel des Gedichts, das an einen ,tabellarischen Lebenslauf‘ erinnert: Denn dort waren viele Lebensjahre, ja sogar Lebensjahrzehnte ${ }^{34}$ des Felix auf knappe 60 Verse (vv. 51-113) verdichtet und die wichtigsten Stationen seines Lebens lediglich in Form von vereinzelten, detailarmen Eckdaten nüchtern aneinandergereiht worden; ${ }^{35}$ allein die zwei erklärenden Exkurse, die in diesen ,Lebenslauf‘ eingebettet sind (Abraham-Exkurs in vv. 61-71, Jakob-Esau-Exkurs in vv. 84-94), hatten von größerer Ausführlichkeit und Emphase gezeugt. Doch mit dem Beginn der Verfolgung in Vers 114 ändert sich die Erzählweise vollkommen: ${ }^{36}$ Die starke Zeitraffung, die das erste Drittel des Natalicium gekennzeichnet hatte, ist aufgehoben, und eine narrative Sequenz löst die vorausgehende deskriptive Sequenz ab. ${ }^{37}$ Außerdem treten neben die Feststellungen und Urteile, die der Erzähler aus der Sicht eines Außenstehenden über die Protagonisten äußert, nun immer wieder direkte Einblicke in ihr Innenleben. Die ,Martyrien“ von Felix und Maximus, jeweils ein einzelnes und auf eine kurze Zeitspanne begrenztes Ereignis, werden also sehr viel breiter, detaillierter und dramatischer beschrieben als alle anderen

34 Felix ist bei der Verfolgung kein junger Mann mehr, wie die Formulierung canis ... annis (vv. 172f.) deutlich macht. Vgl. auch Luongo (1992) 19.

35 In ähnlicher Weise äußert sich auch Fabre (1949) wiederholt über den ersten Teil des Gedichts: ,.... tout cela est raconté sans grand détail, sans insistance particulière, sans aucun relief dramatique“ (365); ,... la première partie de ce poème offre un caractère assez schématique et abstrait...“ (367); ,... l'austérité du debut...“(367).

36 Fabre (1949) 365 setzt diesen Umschwung erst für Vers 198 an. Damit lässt er jedoch außer Acht, dass bereits die Passage über die Verfolgung und das Leiden des Felix (carm. 15,114-197) sehr pathetisch ausgemalt ist.

37 So auch Sciajno (2008) 152 zu vv. 114-119. 
Erlebnisse ihres gesamten bisherigen Daseins. ${ }^{38}$ Damit sind sie eindeutig als die Höhepunkte der beiden Erzählstränge konzipiert, auf die beide Einzelhandlungen zulaufen, die sie aber paradoxerweise nicht erreichen. Denn jeweils am Kulminationspunkt des Geschehens (Felix vor der Hinrichtung, Maximus im Sterben) wird zum anderen Erzählstrang übergeblendet und dadurch Spannung erzeugt bzw. die bereits bestehende Spannung erhöht. ${ }^{39}$ Der Wechsel vom ersten zum zweiten Erzählstrang erfolgt relativ abrupt, denn die mit ergo (v. 194) eingeleitete Zusammenfassung (vv. 194-197) über das Leiden des Felix schließt zwar die Felix-Handlung ab, stellt aber keinen Bezug zu Maximus her und fungiert demnach nicht als Einführung oder Vorbereitung des Erzählblocks über Maximus. Dieser Block setzt ganz unerwartet mit dem Namen seines Protagonisten (Maximus, v. 198) ein und lässt das überleitende, vermittelnde Wort interea (v. 198) erst an zweiter Stelle im ersten Vers folgen. Das Publikum wird also nicht behutsam und allmählich an die Maximus-Episode herangeführt, sondern geradezu in sie hineingestoßen. Das ist insofern überraschend, als die Zuhörer bzw. Leser gedanklich und emotional noch völlig von den Heldentaten des Felix vereinnahmt sein dürften, während Maximus wahrscheinlich nicht mehr allzu präsent ist, da er als eine recht unspektakuläre Figur eingeführt wurde und in den vorausgehenden 72 Versen (vv. 126197) überhaupt nicht am Geschehen teilgenommen hat. Dennoch verzichtet der Autor darauf, durch einen kurzen Rückverweis die Erinnerung des Publikums aufzufrischen und ihm die Figur wie auch die Tat des Maximus wieder ins Gedächtnis zu rufen, sondern schließt stattdessen die Maximus-Handlung übergangslos und unverbunden direkt an die Felix-Episode an. Auf diese Weise werden die beiden Protagonisten mit ihrem gegensätzlichen Verhalten einander unmittelbar und sehr plakativ gegenübergestellt, sodass sich ein Vergleich zwischen ihnen nicht bloß anbietet, sondern regelrecht aufdrängt. Dass ein solcher Vergleich markante Unterschiede und Gegensätze zwischen Felix und Maximus zutage fördern sowie eine gewisse Nachrangigkeit des Maximus erweisen könnte, ist durch die scharfe Trennung sowie die Reihenfolge der beiden Erzählstränge bereits auf formaler Ebene angelegt und suggeriert.

38 Ähnlich Fabre (1949) über den zweiten Teil des Gedichts: „... la seconde [partie, d. Verf.] multiplie et détaille longuement les anecdotes émouvantes et dramatiques ...““(367).

39 Sciajno (2008) 210 zu vv. 198-219 zieht hier einen Vergleich zum Film und spricht sogar von „suspence“. 


\section{Felix vs. Maximus: Heiliger und Märtyrer vs. Mensch und Asket}

Der Ausbruch der Christenverfolgung stellt eine Zäsur in der Biographie des Felix dar, eine Schnittstelle zwischen dem alten Leben als perfekter Christ und dem neuen Leben als echter Heiliger. Denn bis zu diesem Zeitpunkt hat sich Felix zwar wie ein vorbildlicher Christ und Kleriker ${ }^{40}$ verhalten, aber keine besonders aufsehenerregenden oder heroischen Taten vollbracht - schließlich gab es dafür auch (noch) keine Gelegenheit.

Das ändert sich jedoch in der Verfolgung, in der sich Felix zum Ideal-Typus des Märtyrers aufschwingt. Denn mit der Flucht des Maximus konzentrieren sich die Angriffe der Verfolger auf Felix, der nun das Haupt der Gemeinde darstellt (vv. 132-134). ${ }^{41}$ Wie eine $\operatorname{arx}$, mit deren Eroberung die belagerte Stadt fällt, wird er umkämpft (vv. 134-137) ${ }^{42}$ und stellt sich wie ein murus gegen seine Widersacher (v. 171). Diese Vergleiche rücken Felix dezidiert in die Nähe eines epischen Helden, v.a. des pius Aeneas ${ }^{43}$, der sowohl im alltäglichen Leben als auch im Kampfgeschehen eine Führungsrolle einnimmt, gewissermaßen das Schicksal der von ihm abhängigen Gemeinschaft in Händen hält und sich den Feinden tapfer entgegenstellt. Doch zugleich handelt Felix nach dem Vorbild des guten Hirten, der bereit ist, sein Leben für seine Herde zu geben, und erweist sich damit als ein würdiger Nachfolger Christi (vv. 169f.). ${ }^{44}$ Auf diese Weise vereint er am Beginn der Verfolgung den heroischen Kampf nach paganem Muster mit dem christlichen Ideal der Opferbereitschaft zum Wohle der anderen und wird so zum christlichen $\operatorname{Heros}^{45}$.

40 Sciajno (2008) 150 zu v. 108 bezeichnet die Laufbahn des Felix als christlichen „cursus honorum".

41 Basson (2003) 140 wertet das als Beweis für die Führungsrolle des Felix und seine enge Verbindung mit Nola. Luongo (1992) 73f. sieht Felix als Vorläufer der großen Priester- und Bischofsfiguren der Zukunft, denen die Verteidigung der Gemeinde obliege. Zur Rolle und Stellung von Bischöfen in der Spätantike vgl. Rapp (2005).

42 Vgl. Verg. Aen. 5,194; 439. Für weitere Parallelstellen vgl. von Hartel/Kamptner $\left({ }^{2} 1999\right)$ und Ruggiero (1996).

43 Ein Vergleich zwischen Felix und Aeneas wäre sehr aufschlussreich, kann hier jedoch nicht gezogen werden.

44 So auch Luongo (1992) 71. Die Angleichung des Heiligen an den guten Hirten Christus ist laut Sciajno (2008) 188 zu v. 170 ein christlicher Topos.

45 Nach Sciajno (2008) 159 zu vv. 125-155 ist der Held des christlichen Epos der Heilige, dessen topischer Kampf gegen die Verfolger mit Phrasen der traditionellen Epik beschrieben werde. 
Doch mit der Verhaftung wird diese Rolle des christlichen Helden, der aktiv für den Schutz seiner Gemeinde kämpft, ersetzt durch die Folie des Märtyrers ${ }^{46}$, der passiv alle Qualen über sich ergehen lässt und mit seinen Gedanken nur noch bei Gott weilt. Zahlreiche Topoi aus dem Arsenal der Märtyrerliteratur werden in dieser Passage aufgeboten: ${ }^{47}$ Felix ist furchtlos und lässt sich freudig verhaften (v. 177).$^{48}$ Er hat sich vom Diesseits abgekehrt und ist ganz von Gott erfüllt (v. 167; vv. 173f.). Das manifestiert sich auch äußerlich, denn er verjüngt sich trotz seines Alters (et canis florente fide revirescit in annis, / ... , Christi memor, immemor aevi, vv. 172f. $)^{49}$, scheint über sich hinauszuwachsen und strahlt einen überirdischen Glanz aus (vv. 175f.) ${ }^{50}$. Die Qualen im dunklen ${ }^{51}$ Kerker durch die Fesseln und Tonscherben $^{52}$ (vv. 182-186) kann er ertragen, weil er den Beistand des mit ihm leidenden Christus spürt ${ }^{53}$ und sich zugleich die himmlischen Belohnungen für seine Standhaftigkeit ausmalt (vv. 187-193). So sind es wahrhaft eine beata ${ }^{54}$ passio und sacr[ae] poen[ae] (v. 194), die Felix als idealer Märtyrer nach dem Muster anderer Märtyrer durchlebt.

Die explizite oder implizite Annäherung an oder Gleichsetzung mit Vorbilder(n) aus der christlichen Heilsgeschichte (Märtyrer und Christus selbst) stellt somit das konstitutive Element für die Zeichnung des Felix dar. ${ }^{55}$ Felix ist das letzte Glied in einer langen Reihe von christlichen Referenzfiguren und muss neben ihnen bestehen können, ja sie bestenfalls sogar übertreffen, damit seine herausragende Funktion und Position bewiesen und legitimiert sind. Dazu vereint

46 Kirsch (2004) 11 zeigt, dass die Märtyrer eine neue Art von Helden verkörpern, die sich auf andere Weise bewähren als die traditionellen epischen Helden, nämlich z. B. durch Leiden.

47 Vgl. Prete (1983) 154; ähnlich Evenepoel (1989) 173f., jedoch mit Fokus auf Parallelen zur Vita Cypriani.

48 Laut Sciajno (2008) 194f. zu v. 177 ein hagiographischer Topos.

49 Sciajno (2008) 191 zu v. 173 verweist darauf, dass aevum sowohl ,irdische Welt‘ (im Sinne von saeculum) als auch ,Alter` bedeuten kann. Dass die Glaubensstärke den Märtyrer sein Alter vergessen lasse, sei topisch.

50 Laut Basson (2003) 143 ein Zeichen für die gesteigerte Spiritualität des Felix, das in der paganen Literatur und der Bibel viele Parallelen habe. Ähnlich Sciajno (2008) 193f. zu v. 176: Felix erscheine wie ein Halbgott.

51 Laut Basson (2003) 142f. ein Topos.

52 Nach Luongo (1992) 55-60 ein verbreiteter und zudem in Mode gekommener Märtyrertopos.

53 Diese Christusnähe bezeichnet Skeb (1997) 273f. als „Einwohnung Christi“. Nach Sciajno (2008) 204 zu vv. 188-189 ist sie ein hagiographischer Topos. Laut Basson (2003) 142f. wird damit das Leben der Märtyrer als imitatio Christi präsentiert.

54 Basson (2003) 141; 145 verweist darauf, dass Felix in spiritueller Hinsicht von den Leiden profitiert.

55 Das entspricht nach Luongo (1992) 51f. und Basson (2003) 134f. den hagiographischen Konventionen. 
er in kumulativer Weise die Ideal-Eigenschaften unterschiedlichster christlicher Ideal-Typen in seiner Person und wird durch ein solches Konglomerat aus einzelnen Versatzstücken verschiedener Provenienz zu einer hybriden Mosaikfigur. Er verfügt über alle erdenklichen christlichen Tugenden und ist dadurch der modellhafte Typus des in jeder Hinsicht perfekten Christen, ${ }^{56}$ aber kein eigenständiger Charakter mit unverwechselbaren Eigenheiten. Denn wo nur auf die Übereinstimmung mit traditionellen Mustern abgezielt wird, sind persönliche Züge nicht bloß irrelevant, sondern sogar hinderlich: So muss die Individualität dem Stereotyp weichen und die Originalität dem Topos. ${ }^{57}$ Felix wird dadurch selbst zum stereotypen Ideal, zum entrückten und übermenschlichen, fast ,unmenschlichen' Märtyrer und ,Musterheiligen“. Aus diesem Grunde gewinnt er trotz der detaillierten Schilderung seiner Handlungen und Haltungen keine rechten Konturen, sondern bleibt eine unwirkliche und kaum greifbare Figur, die in ihrer Unnahbarkeit und ihrem Pathos dem Durchschnittsmenschen eher fern stehen dürfte.

Anders verhält es sich mit Maximus, der vor der Verfolgung in die Wildnis ${ }^{58}$ geflohen ist (vv. 124f.) ${ }^{59}$ und sich zufrieden (contentus ${ }^{60}$, v. 199) zeigt, der Folter entgangen $\mathrm{zu}$ sein. Doch in der freien Natur setzen ihm Klima, Vegetation und physische Beschwerden zu; Sorgen und Trauer zermürben ihn (vv. 202-210).

Die detaillierte Schilderung weist Parallelen $\mathrm{zu}$ der vorher beschriebenen Situation des Felix auf: Beide Protagonisten erdulden ähnliche Schmerzen durch die Scherben bzw. Dornen (vv. 185f. bzw. vv. 207f.), ${ }^{61}$ beide reagieren darauf in geistig-spiritueller Weise. Diese auffälligen Gemeinsamkeiten fordern einen Vergleich der ,passiones` heraus, und dabei enthüllen sich dann gravierende Unterschiede, die Felix und Maximus radikal voneinander trennen: Felix muss lediglich mit körperlichen Qualen umgehen, Maximus auch mit seelischen (intusque forisque ( dimicat, vv. 208f.); ${ }^{62}$ Felix ist ausschließlich von positiven Überlegun-

56 Ebenso Sciajno (2008) 24. Skeb (1997) 280 sieht Felix sogar als „quasi-Typ[us] Christi“.

57 So auch Luongo (1992) 11 und 34 für die Heiligenbiographien im Allgemeinen.

58 Zur Bedeutung der Einöde, meist der Wüste, für das christliche Denken vgl. Rapp (2005) 105-125.

59 Laut Basson (2003) 137 deutet subita ... tempestate fugatus (v. 124) darauf hin, dass Maximus von einer äußeren Macht zur Flucht gezwungen worden sei. Sciajno (2008) 158f. zu v. 124 wertet die Naturmetapher als Ausdruck von Maximus’ Unschuld und zieht einen Vergleich zu einem vom Unwetter überraschten Vogel.

60 Basson (2003) 140 f. mit Anm. 13 bemerkt, der Kontrast zwischen den Figuren hätte verlangt, dass sich Maximus über seine Flucht ebenso freue wie Felix über seine Verhaftung, doch diese Zeichnung wäre zu negativ gewesen.

61 Ebenso Basson (2003) 144.

62 So auch Basson (2003) 144 mit dem zusätzlichen Hinweis, dass die seelischen Qualen bei Maximus exakt dieselben Empfindungen hervorrufen wie die körperlichen, nämlich ein Brennen 
gen und Gefühlen erfüllt (vv. 187-193), Maximus bloß von negativen Empfindungen (vv. 210-213) ${ }^{63}$; Felix setzt aktiv einen Gedankenprozess in Gang, Maximus reagiert passiv auf das, was über ihn hereinbricht (perfert, v. 209; patitur, v. 210); Felix denkt nur an das Jenseits und die künftigen Belohnungen (vv. 191-193), Maximus an seine Gemeinde (vv. 202f.); bei Felix trennen sich in gleichsam dualistischer Weise Geist und Körper und weilen in verschiedenen Welten (vv. 190-192), ${ }^{64}$ Maximus bleibt in seiner ganzen Person dem Irdischen verhaftet; das körperliche Leid wird bei Felix ausgeblendet bzw. aufgehoben (v. 187), ${ }^{65}$ bei Maximus lediglich gemildert (levat, v. 212) und verdrängt (excludit, v. 213); Anlass und Mittel dazu ist bei Felix ein positives Element, nämlich der Beistand Christi (vv. 188f.), bei Maximus eine negative Komponente, und zwar das seelische Leid (vv. 211-213); Felix spricht kein Gebet, Maximus betet ununterbrochen (v. 206) ${ }^{66}$.

Diese Gegenüberstellung zeigt, dass Maximus eine ganz andere Figur ist als Felix. Er wird nicht nach den Idealen und Topoi diverser Vorbildfolien gezeichnet, sondern erscheint als lebensechte und greifbare Person. Maximus ist kein Stereotyp, sondern ein Individuum, kein Heiliger, sondern ein Mensch - und noch dazu ein gequälter und schwacher, allzu menschlicher Mensch, ein Verlierer in jeder Hinsicht: Er ist vor dem drohenden Tod geflohen und wird nun von ihm, wenngleich in anderer Form, eingeholt; er hat gefürchtet, die Qualen der Folter nicht ertragen zu können, und leidet jetzt ebenso, wie wenn er enthauptet, gefoltert oder verbrannt würde (vv. 200-202); er hat sich dem Martyrium entzogen und kann nun nicht einmal die vergleichsweise geringen Unannehmlichkeiten der Flucht ertragen. Damit scheitert er gleich doppelt: Einmal an dem - zugegebenermaßen hochgesteckten - Märtyrer-Ideal, dann aber auch an der nach rigorosem Verständnis ohnehin inakzeptablen Alternative, der Flucht.

Maximus erscheint folglich als absoluter Gegenpart zu Felix, als negative Kontrastfolie. Er ist das, was Felix nicht ist, und umgekehrt. So sind Maximus und Felix scheinbar als aufeinander bezogene Antitypen konstruiert, die ihre eigene Identität zunächst vornehmlich aus dem Vergleich mit und der scharfen Abgrenzung von ihrem Gegenüber gewinnen. Damit stehen sie an den entgegengesetzten Polen einer Werteskala und verkörpern konträre Kategorien: Stark vs. schwach,

(cura ... urit, v. 203 bzw. uritur igne / frigoris, v. 203f.) und Stechen (conpungitur artus / sentibus et mentem curis, vv. $207 \mathrm{f}$.).

63 Hier fällt die Häufung negativ konnotierter Begriffe auf: tristitiae (v. 210), maesto (v. 210), duris dura (v. 211), cruciatu ... a acerbo (v. 211), tormenta (v. 212), doloris / ... dolor (vv. 212f.).

64 Ähnlich Basson (2003) 143.

65 So auch Basson (2003) 143.

66 Basson (2003) 145 bemerkt zu Recht, dass Maximus trotzdem zunächst keine Hilfe von Gott erfahren dürfe. 
vollkommen vs. fehlerbehaftet - mit einem Wort: heilig vs. menschlich. Diese Unvereinbarkeit der zwei Protagonisten spiegelt sich auf formaler Ebene in den zwei getrennten Erzählsträngen, in die sich die Geschichte mit dem Ausbruch der Verfolgung aufgespalten hat. Die Verfolgung ist damit nicht bloß ein passiver Hintergrund, vor dem sich die einzelnen Ereignisse abspielen, sondern ein aktiver Faktor und sogar Katalysator für die Figurenzeichnung. Denn sie entwirft eine negative Grundsituation und zwingt Felix wie auch Maximus dazu, ihr ,wahres“, so gegensätzliches Gesicht und Wesen zu enthüllen.

Auf den ersten Blick mag eine solch starre und eindimensionale Charakterisierung der zwei Protagonisten als perfekter Heiliger einerseits und schwacher Mensch andererseits zwar naheliegen, doch sie lässt sich nicht halten, da mehrere Textpassagen dazu in offenem und teilweise sehr deutlichem Widerspruch stehen. Hier enthüllen sich neue oder verborgene Züge der Figuren, sodass die Charaktere Felix und Maximus ambivalenter und komplexer sind bzw. werden, als es zuerst scheint.

So fällt zunächst auf, dass Maximus überraschenderweise an keiner einzigen Stelle negativ bewertet ist und überdies auch seine Flucht nirgendwo verurteilt wird. Darin liegt der Schlüssel zum Verständnis dieser Figur und ihrer Bedeutung für das Heiligenkonzept des Felix. Umso erstaunlicher ist es, dass die Flucht des Maximus in der Forschung bisher nur vereinzelt und am Rande thematisiert wurde, z. B. bei Evenepoel (1989; 1991) und Basson (2003), deren Erklärungsversuche jedoch einer Ergänzung und Abänderung bedürfen. Denn beide Forscher liefern richtige und zielführende Ansatzpunkte, die sie dann jedoch aufgeben bzw. unberücksichtigt lassen und/oder gar nicht erst ausführen und weiterentwickeln.

So hatte Evenepoel in seiner ersten Studie noch treffend festgestellt: „... God's miraculous interventions on behalf of both holy men are evidence that nothing censurable was done."67 Diese plausible Schlussfolgerung wird jedoch nicht näher erläutert und für die zweite Studie nicht mehr herangezogen, denn dort erklärt Evenepoel die positive Bewertung des Maximus damit, dass auch der verehrungswürdige Heilige in der zweiten Verfolgung die Konfrontation mit den Verfolgern vermeide. ${ }^{68}$ Eine solche Begründung des früheren Geschehens durch das nachfolgende gewissermaßen aus der Rückschau ist jedoch problematisch, denn sie setzt für das 4. Natalicium bereits die Kenntnis des 5. Natalicium voraus und widerspricht damit der natürlichen Gedichtabfolge: Das Publikum, das im 4. Natalicium fragt, wie die Flucht des Maximus zu beurteilen ist, kann zur Beant-

67 Evenepoel (1989) 173.

68 Evenepoel (1991) $151 \mathrm{f}$. 
wortung dieser Frage schwerlich das ihm noch gar nicht bekannte Folgegedicht heranziehen. Wenn dort dann die Flucht des Felix nicht von Entschuldigungen begleitet wird, begründet Evenepoel das damit, dass Felix seine Tapferkeit bereits im 4. Natalicium unter Beweis gestellt habe ${ }^{69}$ und die Sorge um die Gemeinde als möglicher Grund für die Flucht bereits bekannt sei. ${ }^{70}$ Doch dass die Flucht nur dem Schutz der Gemeinde gedient habe, ist in keinem der beiden Gedichte ausdrücklich erwähnt. Die Sorge um die Gemeinde quält Maximus erst nach der Flucht, nicht bereits zuvor und ist daher allenfalls eine Konsequenz der Flucht, nicht aber ihr eigentliches Motiv.

Basson wiederum stellt die Frage: „Could it be that in this manner Paulinus is seeking to suggest that there was another kind of perfect martyrdom available to Christians?“71 Doch anstatt diese vielversprechende These weiterzuverfolgen, führt er das Fehlen einer Kritik auf den Vergleich zwischen Felix und Maximus zurück: Dieser Vergleich erscheine zunächst asymmetrisch, da Felix der Rangniedrigere sei, ziele aber letztlich darauf $a b$, die Überlegenheit des Felix zu beweisen. „In order to do so he [Paulinus, d. Verf.] somehow has to compare them as though they were equals ${ }^{72}$. ... Explicit censure of Maximus' actions would disturb the symmetry of the comparison. “73 Doch gerade für die Episode über die Verfolgung kann kaum von „equals“ gesprochen werden, da die Protagonisten nahezu in jeder Hinsicht als Gegenpole gezeichnet sind. Eben diese Passage, in der sich die meisten Anhaltspunkte für einen Vergleich der Figuren ergeben, erweist so klar wie keine andere die Ungleichheit von Felix und Maximus. Wenn jedoch eine Symmetrie erst gar nicht gegeben ist, kann sie auch nicht die Begründung für den ausbleibenden Tadel sein.

All diese Erklärungsversuche müssen scheitern, weil sie von der falschen Prämisse ausgehen. Denn sie fußen auf der Annahme, das Ausbleiben einer Kritik an Maximus sei verwunderlich. Damit wird aber davon ausgegangen, dass eine Kritik überhaupt erforderlich sei, und das setzt wiederum voraus, die Flucht des Maximus müsse negativ beurteilt werden.

Doch für eine solche Deutung bietet der Text keine Grundlage, denn Maximus wird nicht nur nicht kritisiert, sondern sogar positiv bewertet - und das an mehreren Stellen und durch mehrere Instanzen in und ,über‘ der Erzählung, nämlich durch Maximus selbst, Felix, Gott und den Dichter.

69 Ähnlich wird in der Vita Cypriani argumentiert (Pont. vita Cypr. 7,13f.).

70 Evenepoel (1989) 173; ähnlich Sciajno (2008) 159f. zu v. 125.

71 Basson (2003) 141 Anm. 13.

72 Hier ist generell zu fragen, ob eine unterlegene Vergleichsfigur die Überlegenheit des Partners nicht deutlicher zeigt.

73 Basson (2003) 136. 
Die persönliche Perspektive des Maximus auf seine Taten findet sich erst sehr spät im Text, und zwar in der Rede ${ }^{74}$ nach seiner Wiederbelebung. Darin betont Maximus, er habe trotz seiner Flucht den Glauben treu bewahrt (vv. 313f.) und sei nicht aus Furcht vor dem Tod oder aus Liebe zum Leben (v. 316f.) geflohen, sondern bloß aus Angst vor seiner körperlichen Schwäche (v. 318). Beweis dafür seien sein Zustand und sein Aufenthaltsort, denn er habe sich nicht in eine Stadt mit all ihren Annehmlichkeiten begeben (vv. 318-320), sondern sein Leben vertrauensvoll in Gottes Hände gelegt (vv. 322-324). ${ }^{75}$

Diese Argumentation wirkt jedoch in manchen Punkten etwas fragwürdig. So erscheint die präzise Unterscheidung zwischen der Furcht vor dem Tod (mortis ... metu, v. 316) und der Furcht vor der körperlichen Schwäche (fragile hoc metuens infirmi corporis, v. 318) wie eine sophistische Spitzfindigkeit. Will Maximus damit sagen, dass er zwar den Tod, nicht aber die Folter und die damit verbundenen Qualen ertragen kann? Wie passt dazu aber die Feststellung, der Bischof habe in der Wildnis die körperlichen Schmerzen tapfer auf sich genommen (vv. 207-213) und seine Hinfälligkeit verachtet (v. 215)? Eine plausible Antwort auf diese Fragen liefert Basson: „... what prompted him [Maximus, d. Verf.] to flee in the first place was not so much the fear of physical suffering tout court, but rather the fear of the deleterious effect of a particular form of suffering on his faith, namely the suffering resulting from torture. " 76 Doch wenn diese Erklärung zutrifft, offenbart Maximus dann nicht einen bedenklichen Mangel an den Eigenschaften, mit denen sich nach christlichem Verständnis auch solche Krisensituationen wie Haft und Folter meistern lassen müssten und die Maximus sehr wohl $\mathrm{zu}$ besitzen behauptet: Glaubensstärke (solido tamen esse fidelis / pectore duravi, vv. 313f.), Gottvertrauen (fiducia, v. 324) und Unterwerfung unter Gottes Willen (in gremio domini dulcis mea colla reponens, / ipso ut deficerem teste aut pascerer ipso, vv. 322f.)?

Wie kann weiterhin der Zustand des Maximus als Beweis dafür gelten (docet et ... status ipse, v. 314), dass der Bischof den Tod nicht fürchtet? Der drohende Tod in der Wildnis ist die unkontrollierbare Folge der äußeren, nicht beeinflussbaren Umstände, nicht aber ein Ziel, das Maximus bewusst gewählt und durch eigenes Handeln angestrebt hat. Denn hätte er den Tod gesucht, so wäre er nicht

$74 \mathrm{Zu}$ dieser Rede vgl. Basson (2003) 138f. Sciajno (2008) 289 zu vv. 309-328 bezeichnet sie treffend als „laudatio sui“, als Panegyricus in Versen, in dem Maximus seine christlichen Tugenden preise.

75 Basson (2003) 139f. wertet die Flucht als einen asketischen Rückzug in die Einöde (140). Dagegen ist einzuwenden, dass Maximus zunächst gar kein Asket ist und nicht durch eine asketische Geisteshaltung zur Flucht veranlasst wird. Zudem sind Einöde und Stadt einander nicht diametral entgegengesetzt, wie Rapp (2005) 136 zeigt.

76 Basson (2003) 139. 
vor der Verfolgung geflohen und hätte zudem wohl kaum auf Felix gewartet oder ihm Vorwürfe wegen der Verzögerung gemacht (vv. 309-312).

Und warum sollte schließlich der Aufenthaltsort des Maximus seine Todesverachtung und Glaubenstreue (docet et locus ..., v. 314) bezeugen? Immerhin ließe sich die Entscheidung, die Städte zu meiden, auch einfach darauf zurückführen, dass die Christenverfolgungen in den Orten systematischer durchgeführt werden konnten als in unbesiedelten Gegenden, sodass in ,Ballungsräumen“ die Gefahr einer Verhaftung erheblich größer war.

Weshalb verfällt Maximus überhaupt in die Rolle des defensor und laudator sui? Empfindet er inzwischen Reue und Beschämung darüber, dass er beim Ausbruch der Verfolgung einen minderwertigen Weg gewählt hat? Und versucht er daher in der Retrospektive, seine Motive und Handlungen nicht nur beschönigend zu rechtfertigen, sondern sogar positiv umzudeuten?

Für sich genommen ließe sich die Rede des Maximus also zumindest in Teilen als (schwache) Ausrede demaskieren und das Bild, das der Bischof von sich selbst zeichnet, als subjektiv gefärbt und deshalb unwahr ablehnen. Doch überraschenderweise wird die Selbstdarstellung des Maximus durch die anderen Instanzen des Natalicium bestätigt und noch unterstrichen.

So äußert Felix bei der Begegnung mit dem Bischof keine Vorwürfe, nicht einmal eine Frage nach dem Grund für seine Entscheidung und lässt weder Verachtung noch Geringschätzung für den Flüchtigen erkennen. Kommentarund regungslos nimmt er seine Rede auf und zeigt danach ebenso viel Aufopferungsbereitschaft wie zuvor. Er hat offenbar vollstes Verständnis für die Tat des Maximus und empfindet die Flucht nicht als ein Zeichen von Feigheit, obgleich sie doch zu seinem eigenen heroischen Verhalten in schärfstem Gegensatz steht.

Gott selbst wiederum bringt Maximus ausschließlich Mitleid, Milde und Güte (pietas, v. 220; sereno / lumine, vv. $230 \mathrm{f}$; mitis pater, v. 232) entgegen und will nicht zulassen ${ }^{77}$, dass der Bischof in der Wildnis zugrunde geht (v. 221; vv. 231f.). Gottes Zuwendung zeigt, dass das Handeln des Maximus kein unentschuldbares Vergehen darstellt, das mit der endgültigen Gottverlassenheit und einem elenden Tod bestraft werden müsste. Und da Gottes Eingreifen in keiner Weise als Akt barmherziger Vergebung für einen bemitleidenswerten Sünder präsentiert wird, bleibt lediglich eine einzige Schlussfolgerung: Maximus bedarf keiner Vergebung, denn er hat überhaupt kein Vergehen begangen. ${ }^{78}$

77 Vgl. die zweimalige, identische Phrase non tulit (v. 221; v. 232).

78 Basson (2003) 137 verweist jedoch darauf, dass manche Kirchenväter (z. B. Augustinus) es durchaus kritisch bewerteten, wenn ein Priester seine Gemeinde bei Gefahr im Stich ließ. 
Doch mehr noch: Maximus ist nicht bloß frei von Schuld, sondern wird vom Dichter mit den ehrenvollen Begriffen confessor (v. 230; v. 339) und martyrium (v. 201) ausgezeichnet und dadurch in genau derselben Weise gepriesen wie Felix. Doch wofür? Maximus musste ja im Gegensatz zu Felix weder Haft noch Folter erleiden, und die Fluchthandlung kann bei aller Unanstößigkeit dennoch nicht den Charakter einer Heldentat annehmen. Damit gibt es nur noch einen Faktor im Leben des Bischofs, der mit den positiv konnotierten Termini confessor und martyrium gemeint sein kann: Das entbehrungsreiche Leben, das Maximus nach seiner Flucht in der Einöde geführt hat. Denn er lebt einsam in der Wildnis (v. 125; v. 198), fastet (v. 205) und schläft auf dornigem ${ }^{79}$ Lager (vv. 207-209). Tapfer kämpft er gegen die Widrigkeiten (dimicat, v. 209) ${ }^{80}$ und ist beständig ins Gebet vertieft. In und trotz seiner Schwäche beweist er unerschütterliche Geistesstärke (vv. 214f.), Duldsamkeit und Verachtung für seine körperliche Hinfälligkeit (v. 215).

Einsamkeit, Selbstkasteiung, Gebet, Konzentration auf das Geistig-Seelische und Negierung der Körperlichkeit - all das sind Topoi, die in der hagiographischen Literatur für Eremiten und Mönche geltend gemacht werden. ${ }^{81}$ Maximus ist also in dieser Passage nach den für Asketen üblichen Kategorien beschrieben und dadurch selbst zum Asketen stilisiert. Zwar sind die körperlichen Unannehmlichkeiten, die er erfährt, weniger selbst auferlegt als vielmehr den äußeren Umständen geschuldet, doch die geistig-seelischen Einschränkungen entspringen allein der persönlichen und freien Willensentscheidung des Bischofs. Maximus wird demzufolge nicht bloß gezwungenermaßen, sondern auch durch seinen eigenen Entschluss zum Asketen.

Die Entwicklung zum Asketen ist letztlich eine direkte Folge von Maximus' Glaubenstreue, denn die Flucht in die Wildnis und die daraus resultierende leidvolle asketische Lebensweise sind nur seinem unbeirrbaren Festhalten am christlichen Bekenntnis geschuldet: Weil der Bischof seinen Glauben nicht verleugnet hat, musste er die lebensbedrohlichen Entbehrungen der Askese auf sich nehmen. Maximus hat folglich allein wegen seines Glaubens gelitten und so definitionsgemäß eine echte confessio $^{82}$, ja sogar ein Martyrium vollzogen, wie es auch explizit formuliert wird (ferebat / martyrium, vv. 200 f.). ${ }^{83}$ Wenn nun aber die

79 Die Dornen evozieren das cilicium des Asketen; zum cilicium vgl. Lienhard (1977) 74.

80 Vgl. Basson (2003) 145.

81 Vgl. dazu die bereits erwähnten Mönchsviten.

82 Luongo (1992) 67 und Basson (2003) 137 verweisen hier auf Cyprians Unterscheidung zwischen öffentlicher und privater confessio: Demnach würde Maximus eine private, Felix eine öffentliche confessio vollziehen.

83 So auch Basson (2003) 143f. Ablehnend dagegen Seng (2006) 485 Anm. 17, allerdings eher beiläufig mit der knappen Begründung, dass Maximus nicht explizit als Märtyrer bezeichnet sei, 
Formulierung ferebat martyrium (vv. 200f.) auf das entsagungsreiche, asketische Leben, das genau genommen natürlich kein Martyrium ist, angewendet werden kann, dann ist die Askese dadurch ausdrücklich als eine weitere, neue und andere Form von Martyrium anerkannt. Dass diese neue Form andere Leiden mit sich bringt als das konventionelle Martyrium, spielt keine Rolle; entscheidend ist lediglich die Tatsache, dass um des Glaubens willen gelitten wird, in welcher Art und Weise auch immer. Die Askese mag zwar anders geartet sein (diversa, v. 200), muss darum aber nicht geringere (non leviore, v. 200) Qualen (cruce, v. 201) mit sich bringen als das Martyrium und darf aus diesem Grund auch denselben Begriff und denselben Rang beanspruchen. Die Askese ist ein symbolisches Martyrium bzw. ein ,Ersatzmartyrium', stellt aber dennoch eine gleichwertige Entsprechung und vollgültige Alternative zum ,echten' Martyrium in seinen vielfältigen Ausprägungen dar, wie bereits aus den einleitenden Versen der Maximus-Episode hervorgeht: diversa at non leviore ferebat / martyrium cruce, quam si ferro colla dedisset / membraque tormentis aut ignibus (vv. 200-202).

Durch diese Anerkennung der Askese als Martyrium darf auch Maximus zumindest implizit als Märtyrer gelten. Dadurch wird er heroisiert und eindeutig in die Nähe des Felix gerückt, sodass die Beziehung der Protagonisten neu definiert werden muss: Beide sind confessores (Maximus in v. 230, Felix bereits zuvor in v. 188), beide ,Quasi-Märtyrer` - auch wenn nur Felix wirklich als martyr (v. 46) bezeichnet wird - und damit nicht mehr Kontrastfolie, sondern wahre Partner und ebenbürtige Gegenüber (digno / condignum comitem, vv. 232f. ${ }^{84}$ ).

Dass sich die Figuren aufeinander zubewegen und einander annähern, wird in doppelter Hinsicht versinnbildlicht: Zum einen räumlich durch die Begegnung der Protagonisten in der Wildnis, mit der sich das bisherige Neben- und Gegeneinander der Figuren in ein Miteinander verwandelt, zum anderen erzähltechnisch durch die Verknüpfung der zuvor getrennten Erzählstränge, mit der die vorausgehenden zwei Einzeldarstellungen nun von einer Paardarstellung abgelöst werden. Verursacht wird diese Veränderung durch den Plan Gottes (vv. 230238), der als positives Element eine Peripetie ${ }^{85}$ in der Erzählung und der Personenzeichnung bewirkt.

sondern bloß mit dem Wort martyrium (v. 201) in Verbindung gebracht werde. Damit grenzt Seng aber die Phrase ferebat / martyrium (vv. 200f.) zu scharf von martyr ab, obwohl sie geradezu eine Erklärung und Definition des Titels ,martyr ${ }^{`}$ darstellt.

84 Laut Sciajno (2008) 233f. zu v. 233 eine Betonung des spirituellen Bandes zwischen Felix und Maximus.

85 Sciajno (2008) 210 zu vv. 198-219 spricht hier von „,vero fulcro della storia“. Dabei sei Gott der eigentliche Protagonist (223 zu vv. 220-221). 
Doch trotz dieser Annäherung sind Maximus und Felix einander nicht gleichgestellt oder gar ranggleich, denn der Bischof ist und wird kein Heiliger, sondern bleibt bei aller Erhöhung immer nur ein Mensch mit menschlichen Emotionen und Schwächen. Er verkörpert also einen völlig anderen Typus als Felix, und damit sind nicht nur die Ausgangsbedingungen, sondern in der Folge auch seine Bemühungen und sein Erfolg anders gelagert als bei Felix. Maximus ist Felix bereits von seiner körperlichen Konstitution her unterlegen, denn er ist alt, wie mehrfach betont wird (senior, v. 120; senis, v. 235; v. 272), und solchen Extrembedingungen nicht (mehr) gewachsen, sodass ihn bald Krankheit und Erschöpfung überwältigen (aeger, v. 198; vv. 213-219). Zudem verfügt er nicht über die übermenschlichen Fähigkeiten wie Heroentum, Rigorismus und Entrücktheit, die dem Heiligen verliehen waren bzw. wurden. Maximus kann den Widrigkeiten lediglich seine menschlichen Kräfte entgegensetzen, doch diese reichen nicht aus, um die schwierigen Umstände $\mathrm{zu}$ bewältigen oder gar $\mathrm{zu}$ überwinden. Darum leidet Maximus unter ähnlichen Bedingungen schwerer als Felix, darum muss er zuletzt kapitulieren. Nicht spirituelle Unzulänglichkeit oder persönliche Charakterschwäche zwingen den Bischof in die Knie, sondern allein die Unzulänglichkeiten und Schwächen, die jedem Menschen qua natura innewohnen. Maximus scheitert, weil er bloß ein Mensch ist, und diese unabänderliche condicio humana trennt ihn unüberbrückbar von Felix, dem über- bzw. unmenschlichen Märtyrer und ,Musterheiligen“.

\section{Vom idealen zum menschlichen Heiligen: Die Verwandlung des Felix durch Maximus}

Aber Felix bleibt nicht der über- bzw. unmenschliche Märtyrer und ,Musterheilige‘, als der er zunächst aufgetreten war. Denn jetzt werden die Wesenszüge und Rollenmuster, die ihn bisher charakterisiert hatten, in ihr Gegenteil verkehrt und/ oder um neue Facetten ergänzt.

So ist zunächst zu konstatieren, dass Felix trotz aller Bemühungen letztendlich eben doch kein Märtyrer wird. Dabei hatte es zunächst so ausgesehen, als seien die Passagen, in denen sich Felix bereits während der Haft als idealer Märtyrer geriert hatte, lediglich die Vorstufe und Vorbereitung zu einem noch spektakuläreren Auftritt beim eigentlichen Martyrium. Doch diese anvisierte und ersehnte Klimax bleibt aus, und die Erwartungen des Publikums wie auch des Heiligen werden ge- bzw. enttäuscht, denn Felix wird vor dem Martyrium aus dem Kerker befreit. Damit ist ihm die Gelegenheit genommen, sich wirklich bis zur Vollendung als Märtyrer zu bewähren und sein heiligmäßiges Leben mit dem 
höchsten christlichen Verdienst, dem Märtyrertod, zu krönen. Dieses Ziel, das zuvor sein ganzes Denken und Handeln bestimmt hatte, kann er nicht erreichen und folglich auch die an ihn gestellten Ansprüche nicht erfüllen. Denn nun wird sich nie mehr zweifelsfrei feststellen lassen, ob Felix weiterhin so überschwängliches Lob verdient und die bereits übernommene Rolle des perfekten Märtyrers auch tatsächlich ausgefüllt hätte. Schließlich bleibt Felix - wenngleich nicht durch eigenes Versagen - gleichsam auf halbem Wege stehen: Er hat für seinen Glauben gelitten, aber nicht mit seinem Leben dafür bezahlt. Damit ist er nach kirchlicher Definition ein confessor, der bestenfalls als Märtyrer zweiter Klasse gilt, den Ehrentitel ,Märtyrer‘ aber streng genommen nicht verdient. Wenn Felix trotzdem als Märtyrer gefeiert wird, so wirkt das wie eine panegyrisch-dichterische Überhöhung, in der die biographische ,Realität‘ unterschlagen bzw. verfälscht wird. Denn Felix ist kein idealer, ja nicht einmal ein ,richtiger‘ Märtyrer, sondern nur ein verhinderter und gescheiterter Märtyrer, ein - wenngleich im positiven Sinne zu verstehen - ,Möchtegern-Märtyrer‘.

Zudem ist Felix auch mitnichten ein Musterheiliger, wie sich bei seiner Befreiung aus dem Gefängnis dann sehr deutlich zeigt, wenn man diese Szene mit ihrer Vorbildfolie aus der Apostelgeschichte, nämlich der Befreiung des eingekerkerten Apostels Petrus (Vulg. act. 12,6-11), vergleicht. ${ }^{86}$ Einen solchen Vergleich zieht Paulinus selbst, wenn er die Befreiung des Felix als eine Wiederholung von Petrus' Befreiung versteht (veterem remeare recenti / historia video speciem, Paul. Nol. carm. 15,260 f.). ${ }^{87}$ Felix wird damit einer weiteren prominenten Figur der christlichen Heilsgeschichte gegenübergestellt, und das liegt insofern nahe, als sich Felix und Petrus in einer vergleichbaren Grundsituation befinden: Beide liegen wegen ihres Glaubens unter strenger Bewachung im Gefängnis in Ketten und erwarten die Gerichtsverhandlung bzw. das Martyrium (Vulg. act. 12,4-6; Paul. Nol. carm. 15,178-185); beide werden in der Nacht von einem strahlenden Engel aufgesucht (Vulg. act. 12,6f.; Paul. Nol. carm. 15,238f.), ${ }^{88}$ der sie mitten durch die (schlafenden) Wächter und die zuvor verschlossenen Tore ins Freie führt (Vulg. act. 12,10; Paul. Nol. carm. 15,253-255), sodass sie die Aufgabe vollbringen können, die ihnen von der göttlichen Vorsehung zugewiesen ist.

86 Fabre (1949) 365-367 vergleicht die Befreiung des Felix nicht mit der Episode in der Apostelgeschichte, sondern mit Raffaels Fresko in der Stanza di Eliodoro im Vatikan. Ein solcher Vergleich ist jedoch nicht unproblematisch, denn das 4. Natalicium und das Fresko gehören verschiedenen Darstellungsformen und Epochen an.

87 Laut Sciajno (2008) 236 zu vv. 238-265 wird dadurch unterstrichen, dass die göttliche Gnade in den Heiligen zu jeder Zeit aktiv ist.

88 Der Kontrast zwischen Licht und Dunkelheit wird von Fabre (1949) 366f. besonders hervorgehoben. 
Innerhalb dieser gleichen Rahmenbedingungen sind jedoch markante Unterschiede zwischen den beiden Episoden zu erkennen, sowohl im Hinblick auf die Details der Befreiung als auch ganz besonders auf die Reaktion der beiden Heiligen. ${ }^{89}$ Als der Engel erscheint (Vulg. act. 12,7; Paul. Nol. carm. 15,238f.), schläft Petrus und muss erst durch einen Stoß geweckt werden (percussoque latere, Vulg. act. 12,7); Felix dagegen scheint von selbst erwacht oder bereits wach zu sein, denn der Engel spricht ihn an, ohne zuvor ,handgreiflich` zu werden (Paul. Nol. carm. 15,241). Während Petrus angesichts der Erscheinung vollkommen ungerührt bleibt, erschrickt Felix zunächst über den Lichtglanz und die Stimme des Engels, hört dann aber seine Worte gläubig an (vv. 242f.). Petrus wie auch Felix halten das Geschehen für einen Traum (Vulg. act., 12,9; Paul. Nol. carm. 15,244f.), doch diese Empfindung tritt in unterschiedlichen Phasen der Befreiung ein und hat auch unterschiedliche Auswirkungen auf das Handeln der Protagonisten: Petrus glaubt sich erst dann in einem Traum befangen, als er dem Engel aus dem Kerker folgt (Vulg. act. 12,9), und kommt ohne Fragen und Zaudern allen Befehlen stets sofort nach; Felix dagegen befürchtet bereits gleich nach der Erscheinung des Engels, dass die an ihn gerichteten Weisungen bloß ein Trug sind (Paul. Nol. carm. 15,244f.), und zögert daher voll Staunen und Angst (stupet anxius, v. 245). Zuletzt wendet er sogar ein, er könne die Aufforderung des Engels nicht befolgen, weil er durch die Kette, den Riegel und den Gefängniswärter daran gehindert werde (vv. 245-248). Diese so realitätsnahe, pedantisch-umständliche Entschuldigung bildet gewissermaßen den grotesken Gipfelpunkt der Episode, in dem sich alle Regungen des Felix bündeln: Furcht und Schrecken, Staunen und Zögern, Zweifel und Kleingläubigkeit, mangelndes Vertrauen in Gottes Allmacht und sogar einen Hauch von Widerspruchsgeist. Damit hebt sich Felix stark von Petrus ab, der kommentarlos alles tut, was von ihm verlangt wird, und stets ruhig und gelassen, nahezu emotionslos bleibt.

Allerdings, so ließe sich an dieser Stelle einwenden, könnte die abweichende Reaktion des Felix auf das völlig anders geartete Vorgehen des Engels zurückzuführen sein. Denn Petrus erhält drei Mal relativ knappe, aber sehr genaue und pragmatische Anweisungen: Er soll aufstehen (surge velociter, Vulg. act. 12,7), sich ankleiden $(12,8)$ und dem Engel folgen $(12,8)$. Der Apostel wird also von seinem Erwachen bis zum Verlassen des Kerkers langsam und schrittweise angeleitet und gelenkt. Worauf diese Einzelschritte letztlich abzielen, nämlich die Befreiung aus

89 Fabre (1949) 366 sieht dagegen ausschließlich Gemeinsamkeiten: „... le même étonnement, la même stupeur du saint, la même impression de rêve, la même hésitation, puis la même obéissance à suivre, sans comprendre, l'envoyé du ciel“. Diese Feststellung mag für den Vergleich zwischen dem 4. Natalicium und dem Raffael-Fresko zutreffen, nicht aber für die Gegenüberstellung des 4. Natalicium und der Apostelgeschichte. 
dem Gefängnis und die Rückkehr zur Gemeinde, versteht Petrus erst im Nachhinein (12,11). Felix dagegen erhält keine Teilbefehle, sondern es ist nur sehr unpräzise von verbum (Paul. Nol. carm. 15,243) und mandata dei (v. 245) die Rede, womit zweifellos die Rettung des Maximus gemeint ist, die aber nicht klar kommuniziert oder langsam vor- bzw. aufbereitet wird. Im Gegensatz zu Petrus kennt Felix also zwar das Ziel, das ihm vorgegeben wird, bekommt aber keine Instruktionen und Hilfestellungen, wie er zu diesem Ziel gelangen kann, das ohnehin scheinbar jenseits aller Erreichbarkeit liegt und menschliche Vorstellungskraft übersteigt: Wie sollte Felix, der selbst im Gefängnis sitzt, die ihm übertragene Mission erfüllen können? Felix ist somit überfordert - nicht unbedingt von der Aufgabe an sich, wohl aber von der Art und Weise, wie sie ihm gestellt und präsentiert wurde. Und so bleibt dem Engel nichts anderes übrig, als seine Erwartungshaltung nach unten zu korrigieren und den Gesamtauftrag in kleinere, überschau- und machbare Teilaufträge zu ,portionieren'. Dazu greift er auf die schon bei Petrus angewendete Taktik zurück und erteilt einen unmissverständlichen Befehl: Er fordert Felix auf, sich zu erheben (iubet ... adsurgere, v. 249). Diese Anweisung am Ende des Dialogs zwischen Felix und dem Engel ist identisch mit derjenigen, die Petrus gleich zu Beginn seiner Befreiung vernimmt. Es scheint fast, als würde dadurch die etwas unglückliche Begegnung zwischen Felix und dem Engel ,auf null zurückgesetzt' und ein zweiter Versuch gestartet, der nach den Erfahrungswerten und Mustern der Petrus-Episode verläuft und deshalb möglicherweise größeren Erfolg verspricht.

Diese andere, weitaus kompliziertere Vorgehensweise des Engels ist zwar eine Erklärung, offensichtlich aber keine Rechtfertigung oder Entschuldigung für das Gebaren des Felix. Denn immerhin richtet der Engel einen scharfen Tadel an den Heiligen (morantem / increpitans, vv. 248f.) und gibt damit indirekt zu verstehen, dass er dessen Einwände für eine bloße Verzögerungstaktik und billige Ausflucht hält. Hier ist die vormalige Charakterisierung des Felix auf den Kopf gestellt: Statt Lob und Bewunderung, die bisher die Darstellung dominiert hatten, wird jetzt herbe Kritik laut, und dadurch ist das Verhalten des Felix, das zuvor stets als tadellos und vorbildlich beschrieben worden war, nun ausdrücklich als unangemessen gebrandmarkt. Felix ist damit tief gefallen: Vom gefeierten, übermenschlichen Ideal-Märtyrer und Ideal-Heiligen, der in der Verfolgung alle Gefahren spielend gemeistert hatte, ist er zum gerügten Menschen geworden, der selbst mit einer unkomplizierten Situation wie der Befreiung intellektuell, emotional und spirituell überfordert ist. Er ist so eng in die menschlich-irdische Realität eingebunden, dass seine bisherigen übermenschlichen Ideal-Eigenschaften wie Furchtlosigkeit, Entschlossenheit, Gottvertrauen und Entrücktheit gänzlich verschüttet und begraben scheinen. Felix ist nicht mehr imstande, seine früheren Leistungen zu wiederholen, die zuvor gesteckten Maßstäbe zu erreichen 
und seinen bisherigen Status zu wahren. Er scheitert folglich an seiner eigenen Person und seiner eigenen Vergangenheit, und dadurch rückt in nächster Konsequenz auch sein Vorläufer Petrus in weite Ferne: Denn wenn Felix nicht einmal dem Vergleich mit seinem früheren Selbst standhalten kann, wie sollte er sich dann auch nur im Entferntesten mit dem Apostelfürsten, einem zentralen Repräsentanten der christlichen Heilsgeschichte, messen können?

Die Zeichnung des Felix und sein Verhältnis zu christlichen Vorlagefolien haben sich demnach gewandelt: Bisher war Felix an seine Vorgänger angenähert, mit ihnen gleichgesetzt oder sogar über sie gestellt worden; aus dem Vergleich ergab sich somit seine Ebenbürtigkeit und möglicherweise sogar Überlegenheit. Jetzt aber wird der Heilige von den Vorbildern, zu denen sogar sein eigenes vergangenes Selbst gehört, abgesetzt und abgegrenzt; der Vergleich fällt zu Ungunsten des Felix aus und enthüllt seine Ungleichheit und Unterlegenheit. Felix steht nicht mehr auf einer Stufe mit den ,Musterheiligen', sondern ist von ihnen durch eine Kluft getrennt, die er selbst geschaffen hat - und zwar durch seine menschlichen Emotionen und (Re-)Aktionen. Sie trennen ihn von den vollkommenen Referenzfiguren mit ihren idealen Eigenschaften wie auch von seiner eigenen Vergangenheit als Idealfigur und rücken ihn in die Nähe der Menschen mit all ihren Unvollkommenheiten, Unzulänglichkeiten und Problemen.

Diese Tendenzen zur Emotionalisierung und Vermenschlichung des Felix, die sich bereits bei der Befreiung aus dem Gefängnis abgezeichnet haben, verstärken sich noch bei der Rettung des Maximus, die den spannungsreichen Höhepunkt ${ }^{90}$ der zweiten Hälfte des 4. Natalicium darstellt. Zwar findet Felix kurzfristig seine Unerschütterlichkeit (constante passu, v. 269) wieder, doch mit seiner Ankunft bei Maximus brechen erneut - und weitaus stärker als zuvor - Gefühle auf. Felix ist voller Trauer (maestus, v. 273), als er den Sterbenden sieht, obwohl er ihn noch gar nicht erkannt hat. Sobald er jedoch feststellt, dass es sich um Maximus handelt, wirft er sich über ihn, umarmt und küsst ihn (vv. $274 \mathrm{f}$.). In ängstlicher Sorge (anxius, v. 282) bemüht er sich um den Bischof, doch seine Rettungsmaßnahmen (vv. 276-281) bleiben trotz kundiger Diagnose des Leidens erfolglos, weil es an den notwendigen Hilfsmitteln fehlt (vv. 282-286). Die medizinischen Kenntnisse und der gute Wille des Felix sind in dieser Situation nicht ausreichend, menschliche Hilfe versagt. Als Felix daraufhin in seiner Verzweiflung ein Gebet an Gott richtet (vv. 287-289), wächst auf wundersame ${ }^{91}$ Weise ein Weinstock (vv.

90 So auch Sciajno (2008) 255f. zu vv. 272-273.

91 Basson (2003) 146f. sieht die Rettung des Maximus im Gegensatz zur Tränkung des Felix in der Zisterne nicht als Wunder, weil dabei kein Naturgesetz verletzt werde und Maximus weiter auf Felix angewiesen sei. Das greift jedoch zu kurz, denn das Überleben des Maximus ist maßgeblich der Entstehung des Weinstocks geschuldet und dabei handelt es sich zweifellos um ein Wunder; so 
289-292), sodass Felix den Bischof mit dem Traubensaft wiederbeleben kann (vv. 292-306).

Hier werden am spezifischen Beispiel und über die individuelle Figur des Felix, subtil in die Erzählung verpackt, generelle theologische Konzepte vorgestellt und anschaulich vermittelt: Der Umgang mit Not und das richtige Beten und das angemessene Verhalten angesichts göttlichen Wirkens sowie die Rolle der Heiligen und die Natur des Wundergeschehens.

So lebt Felix vor, wie ein Christ mit einer Krise und dem Leiden eines Mitmenschen umgehen sollte: Er muss sich mitleidig und eifrig mit all seinen Kräften für den Nächsten einsetzen, dabei aber gleichzeitig voller Demut die Begrenztheit menschlicher Fähigkeiten anerkennen. Hat er die ihm $\mathrm{zu}$ Gebote stehenden Möglichkeiten ausgeschöpft und dennoch keinen Erfolg zu verzeichnen, so muss er sich in der festen Zuversicht, dass Gott in seiner Allmacht auch eine aussichtslose Lage zum Guten verändern kann, vertrauensvoll im Gebet an Gott wenden.

Diese Hinwendung an Gott erfordert eine bestimmte geistig-seelische Haltung, die an zwei Stellen für zwei verschiedene Zeitphasen entwickelt wird: Das Gebet des Felix (vv. 287-289) zeigt, was während der Bitte um göttliche Hilfe zu beachten ist, die Tränkung des Maximus (vv. 292-302) demonstriert, wie nach der Erhörung der Bitte das Wirken Gottes aufzunehmen ist.

Bezüglich des Gebets (vv. 287-289) ist zunächst festzuhalten, dass Felix nicht in eigener Sache betet, sondern für seinen leidenden Nächsten, der nicht imstande ist, sein Anliegen selbst zu artikulieren. Damit beweist Felix Nächstenliebe und Uneigennützigkeit, denn er übermittelt die Bitte eines anderen an Gott und setzt sich bei Gott für diesen Menschen ein. Und so ist auch die Bitte ausschließlich auf den Bedürftigen und seinen Vorteil ausgerichtet, während der Betende sich mit seinen eigenen Befindlichkeiten (Ängste, Zweifel, Mühen) komplett zurücknimmt. Felix hat offensichtlich aus der Begegnung mit dem Engel im Kerker gewissermaßen ,dazugelernt', denn er verhält sich nun ganz anders: Anstatt zögerlich und unentschlossen einen entschuldigenden Einwand vorzubringen und damit indirekt seine prinzipielle Eignung sowie die Erfüllbarkeit des Auftrags anzuzweifeln, stellt er jetzt knapp und präzise eine einzige, sehr pragmatische Frage (quaerenti, v. 287), nämlich die Frage ,wie?‘: Er möchte wissen, mit welchen Mitteln und auf welche Weise er die Aufgabe erfüllen kann (quanam ope quave via iussum conplere valeret / servitium, vv. $288 \mathrm{f}$.). Dabei wird bereits durch die Phrase iussum conplere ... servitium (v. 288f.) signalisiert, dass Felix seinen Auf-

auch Sciajno (2008) 267f. zu vv. 289-290; 269 zu vv. 389-302; 270f. zu v. 292. Das Dilemma lässt sich lösen, wenn man zwei Arten von Wundern unterscheidet: ,Direkte‘ Wunder, die sich von Gott unmittelbar an den Bedürftigen selbst richten (Rettung des Felix), vs. ,indirekte‘ Wunder, die dem Notleidenden durch eine Zwischeninstanz vermittelt werden (Rettung des Maximus). 
trag persönlich erledigen und das Begonnene selbst $\mathrm{zu}$ Ende führen will. Er erwartet nicht, dass Gott ihm die Arbeit abnimmt und eine prompte, fertige Lösung liefert, sondern nur, dass er die nötigen Bedingungen dazu schafft. Der Mensch, so ist hieraus zu schließen, darf zwar sein Problem vor Gott tragen und dessen Unterstützung erflehen, sich aber nicht jeder eigenen Mühe und Verantwortung entledigen.

Was im Gebet des Felix (vv. 287-289) nur kurz angedeutet war, wird im Bericht über die Tränkung des Maximus (vv. 292-302) wieder aufgegriffen und vertieft. Denn als mit der Entstehung des Weinstocks (vv. 289-292) die Voraussetzung für die Rettung des Maximus erfüllt ist, legt Felix nicht die Hände in den Schoß, sondern sorgt dafür, dass Maximus von dem zu seinen Gunsten gewirkten Wunder auch tatsächlich profitieren kann. Schließlich ist dem bewusstlosen Bischof durch die bloße Existenz des Weinstocks noch nicht geholfen. Indem Felix den Traubensaft in den Mund des Maximus träufelt (vv. 294-302), überbrückt er die Distanz zwischen dem Weinstock und dem Bischof und führt damit gleichsam das Wunder(-objekt) mit dem ihm zugedachten Adressaten zusammen. Felix übermittelt also das göttliche Wirken an die Menschen und leitet das zu ihrem Wohl gewirkte Heil an sie weiter. Hier kristallisiert sich das fein abgestimmte und harmonische Zusammenspiel zwischen Gott und dem Heiligen bzw. jedem Menschen, der sich wie der Heilige von Gott in Dienst nehmen lässt heraus: Gott ermöglicht das Unmögliche, z. B. durch die Änderung einer bestehenden Situation oder die Bereitstellung von zuvor nicht vorhandenen Mitteln und Fähigkeiten, doch sein Wirken wird erst dann endgültig wirksam und erfahrbar, wenn der Heilige/Mensch es aufgreift, fortführt und weiterträgt. Das göttliche Wirken bzw. das von Gott gewirkte Wunder dient folglich nur als Hilfestellung für die Menschen, es enthebt sie nicht ihres eigenen Handelns im Rahmen ihrer Möglichkeiten.

Im Beten und Handeln des Felix sind demnach die komplexen Konzepte über die Funktion und Stellung des Heiligen durch das praktische Handeln des Felix exemplifiziert und illustriert: Felix übermittelt in seinem Gebet die Anliegen der Menschen an Gott/Christus und tritt somit als ihr Fürsprecher auf; bei der Tränkung des Maximus übermittelt er dann die göttlichen Wunder an die Menschen und fungiert demnach als Werkzeug Gottes/Christi, ${ }^{92}$ der in ihm und durch ihn

92 Skeb (1997) 278f. unterscheidet daher zwei Richtungen der Vermittlung: Vom Menschen zu Christus („Gebetsmittlerschaft“, 279) und von Christus zum Menschen (Heilsmittlerschaft). Ebenso Kirsch (2004) 75f.: Die Heiligen seien Mittler „einerseits des von Christus zu den Gläubigen strömenden Heils, anderseits der Gebete und Bitten der Gläubigen zu Christus, der dann wieder durch sie seine Wunder wirkt“. 
wirkt. ${ }^{93}$ Die primäre Aufgabe des Felix bzw. aller Heiligen, die er hier stellvertretend repräsentiert, besteht also darin, ein (Ver-/Über-)Mittler zwischen zwei getrennten Instanzen zu sein und Gott/Christus in seiner Sphäre mit den Menschen in ihrer Welt zu verbinden. ${ }^{94}$ Damit ist der Heilige auf einer Zwischenebene zwischen den Menschen und Gott/Christus angesiedelt: Er steht durch seine besonderen Verdienste zwar hoch über den Menschen, bleibt aber trotz allem Gott/Christus als Helfer und Diener untergeordnet.

Ganz im Einklang mit diesen Konzepten des Heiligen steht dann auch die Darstellung des Wundergeschehens. So fällt auf, dass das Wunder nicht von dem Heiligen selbst gewirkt wird: Felix erscheint nicht als Wunderheiler, der aus eigener Kraft Kranke gesund macht oder Sterbende zum Leben erweckt, und auch nicht als Wundertäter, der die fehlenden Hilfsmittel einfach ,herbeizaubert` oder aus dem Nichts entstehen lässt. ${ }^{95}$ Selbst nach dem Gebet erhält er keine eigenen Wunderkräfte, sondern ist weiterhin völlig auf Gottes Eingreifen angewiesen und von ihm abhängig. Dieses Fehlen von wundertätigen Kräften unterscheidet Felix auffällig von den Mönchsheiligen Martin und Hilarion, die Wunder um Wunder $\operatorname{tun}^{96}$ und dabei bisweilen fast in eigener Machtfülle und Autorität aufzutreten scheinen. Der Bericht über die Rettung des Maximus zeigt dagegen deutlich, dass der Bischof genau genommen nicht von Felix, sondern allenfalls durch Felix und von Gott/Christus gerettet wird: Gott/Christus lässt den Weinstock wachsen, Felix tränkt den Bischof. Die Wunderhandlung geht ausschließlich von Gott/Christus aus und verweist auf ihn zurück: Gott/Christus ist der alleinige Urheber der wunderhaften Rettung des Maximus wie auch jedes anderen Wundergeschehens; Felix bzw. der Heilige ist nur der Helfer und Vermittler des Wunders, kann es aber

93 Ebenso Kirsch (1983) 333 sowie (2004) 75f. und Skeb (1997) 272 mit der prägnanten Aussage: „Die virtutes des Heiligen beruhen auf der Kraft Christi“. Dieses Konzept gilt natürlich für alle wundertätigen Heiligen, wird aber in der Felix-Biographie besonders klar vorgestellt. Laut Basson (2003) 146 wird die Rolle des Felix als „divine intermediary“ dadurch betont, dass die eigenen Versuche des Felix erfolglos bleiben und erst das Gebet eine Wirkung zeigt.

94 Nach Beinert (1983) 44f. ist das Konzept von einer Mittlerfunktion der Heiligen problematisch, u. a. deshalb, weil es die alleinige Mittlerschaft Christi untergräbt und ,eine Art überirdische[n] Instanzenzug“ (45) schafft, der den Verdacht des Polytheismus aufkommen lässt. Dennoch setzte sich das Konzept durch, denn damit konnte man das Leben der Heiligen als Nachfolge Christi präsentieren (Angenendt 1994, 83), die Gegenwart Christi in den Heiligen beweisen (Skeb 1997, 275f.) und so nicht nur „Christi Heil zu allen Zeiten erfahrbar ... machen“ (Skeb 1997, 276), sondern auch das Wirken der göttlichen Vorsehung in der Welt abbilden (Sciajno 2008, 26).

95 Als Wundertäter tritt Felix erst nach seinem Tod auf. Vgl. Kirsch (2004) 90: „Solange er am Leben ist, geschehen die Wunder an ihm, von seinem Tode an wirkt er die Wunder selber“; ähnlich Evenepoel (1989) 170.

96 So auch Evenepoel (1991) 151. 
nicht aus eigener Macht und Kraft wirken. Hier ist die kirchliche Lehre von der theo-/christozentrischen Natur des Wunders in ein allgemein verständliches Bild gefasst.

Ein solches Wunder wirkt sich, wie dann explizit beschrieben wird, nicht nur auf den eigentlichen Nutznießer, den bewusstlosen Maximus, aus, sondern auch auf die Mittlerfigur, der hl. Felix. Felix erfährt die wundersame Entstehung des Weinstocks als mun[us] (v. 293), das ihn mit Freude erfüllt (laetatur, v. 293) und zugleich auch stärkt und erquickt (divinitus ... refectus, v. 292). Er wird also körperlich, emotional und spirituell aufgebaut, sodass er die Strapazen vergessen und mit neuer Kraft seine Bemühungen um Maximus wiederaufnehmen kann, die ihm noch ein gehöriges Maß an Stärke (luctante manu rigidos paulisper hiatus / laxavit, vv. 300f.) und Geduld abverlangen werden. Die positive Wirkung des Wunders kommt demnach nicht nur dem Adressaten zugute, sondern strahlt auch auf den Vermittler aus und lässt auf diese Weise alle Beteiligten in irgendeiner Form an der göttlichen Gnade teilhaben.

In der Passage über die Rettung des Maximus werden folglich, unaufdringlich ins Geschehen eingebettet, verschiedene aktuelle und viel diskutierte Themen des christlichen Glaubens verhandelt. Diese Themen muten zwar zumindest teilweise recht theoretisch und realitätsfern an, betreffen aber letztlich jeweils einen bestimmten Bereich des tatsächlich praktizierten und gelebten Glaubens, sei es nun die praktische Umsetzung des Gebotes der Nächstenliebe, das Gebet oder der Heiligenkult, und besitzen dadurch eine nicht zu unterschätzende Relevanz für das (tägliche) Leben der gläubigen Menschen. Der (gläubige) Mensch und sein Alltag sind damit die elementaren und konstitutiven Bestandteile dieses Textabschnitts: Auf sie zielt die Erzählung ab, über sie berichtet sie, von ihnen ist sie geprägt.

So gewinnt das Gedicht eine neue Ausrichtung, die der bisherigen diametral entgegengesetzt ist: Während die Episode über die Haft des Felix ausschließlich um das Übermenschliche (übermenschliche Tapferkeit, übermenschliche christliche Tugenden) und Außergewöhnliche (Ausnahme-Rolle des idealen Märtyrers in der Ausnahme-Zeit der Verfolgung) kreiste, stehen jetzt das Menschliche und das Übliche im Zentrum. Maximus ist ein durchschnittlicher Mensch mit gewöhnlichen menschlichen Schwächen (Alter, Konstitution) und menschlichen Gefühlen (Sorge, Trauer, Schmerz) und befindet sich in einer Situation, die zwar zunächst äußerst exotisch anmutet, sich im Grunde genommen aber auf herkömmliche Probleme der prekären menschlichen Existenz reduzieren lässt: Obdachlosigkeit, Hunger, Kälte und Krankheit. Über seine zwischenmenschliche Beziehung zu Maximus wird dann auch der Heilige mit den alltäglichen Bedingungen menschlichen Daseins konfrontiert und entwickelt in der Folge selbst menschliche Gefühle. Diese Gefühle lassen sich in zwei Kategorien einteilen: Die Gefühle von Men- 
schen einerseits und die Gefühle für Menschen andererseits. Felix empfindet also wie die Menschen und er empfindet für die Menschen. Die Gefühle der ersten Kategorie, d.h. die menschlichen Regungen, offenbaren sich dann, wenn man das Verhalten des Felix bei der Befreiung aus dem Gefängnis wie auch bei der Rettung des Maximus mit seinem Gebaren in der Haft vergleicht: Während Felix damals allen menschlichen Emotionen enthoben und entrückt schien, wird er nun von Bedenken und Zweifeln, Ängsten und Sorgen gequält; während er zuvor der Folter und Hinrichtung heroisch entgegengesehen hatte, ist er jetzt aufgewühlt und erschüttert angesichts von Leid und Tod; und während er ehemals gedanklich bereits im Jenseits weilte, ist er nun ganz dem Diesseits und seinen Problemen verhaftet. Die Gefühle des Felix für die Menschen wiederum enthüllen sich allein während der Rettung des Maximus: Felix, der zuvor so unnahbar und distanziert erschien, legt jetzt Hilfsbereitschaft, (Mit-)Menschlichkeit, Anteilnahme, Fürsorge für Schwache und pietas ${ }^{97}$ an den Tag; er ist auf den Dienst am Nächsten konzentriert, anstatt voll Egoismus auf sein eigenes Martyrium fixiert zu sein. Felix macht somit gewissermaßen eine Vermenschlichung durch und wird dadurch zu einem menschlichen Heiligen.

Diese Menschlichkeit ist eine völlig neue Seite des Felix, die er bisher entweder gar nicht besaß oder nur nicht zeigen konnte, weil sie nicht zum typischen Verhaltenskatalog eines Ideal-Märtyrers oder Ideal-Heiligen gehörte und demnach auch nicht durch die Folien vorbildlicher Referenzfiguren vorgegeben war. Da sich Felix jedoch in zunehmendem Maße von solchen Vorbildern und ihren klischeehaften, stereotypen Eigenschaften ,abnabelt', kann er lebensnahe und individuelle Züge gewinnen, die ihm Persönlichkeit und Plastizität verleihen. Felix ist folglich auf dem besten Weg, sich vom Typus zum Charakter zu wandeln.

Die Entwicklung zum eigenständigen Charakter und die Distanzierung von Musterfiguren bringen jedoch notwendigerweise auch eine Abkehr von deren Mustereigenschaften mit sich. Felix verliert damit seinen Nimbus als perfekte Verkörperung des idealen Märtyrers und Heiligen und wird auf ein menschliches Normalmaß ,zurechtgestutzt' bzw. ,geerdet‘. Das wirkt auf den ersten Blick wie eine Degradierung und Profanierung des Felix, ist aber in Wirklichkeit eine Bereicherung. Denn nur wenn Felix aus der Höhe seiner Ideale in die ,Niederungen' der irdischen Realität wie auch des menschlichen Daseins hinabsteigt und das alltägliche Leben der gewöhnlichen Durchschnittsmenschen kennenlernt, kann er für sie zu einer authentischen Vorbild- und Identifikationsfigur sowie zu

97 Die Begriffe pius und pietas finden sich auch an anderen Stellen des 4. Natalicium (v. 67; v. 104; v. 153; v. 240), treten aber in der Episode über Felix und Maximus gehäuft auf (v. 282; v. 293; v. 327; v. 333) und sind (mit Ausnahme von v. 293) nicht mehr auf den korrekten Umgang mit dem Göttlichen, sondern auf den Mitmenschen bezogen. 
einem verständnisvollen Ansprechpartner und Fürsprecher werden. ${ }^{98}$ Um den Menschen nahe zu sein, muss er ihnen erst nahekommen und dazu seine früheren Ideale opfern.

Diese Nähe zu den Menschen stellt jedoch eine Entschädigung und Kompensation für die Aufgabe des bisherigen Status (Ideal-Märtyrer) und Lebensziels (Martyrium) dar, wie der Segnung des Felix durch Maximus (vv. 354-361) am Ende des Gedichts zu entnehmen ist. Denn Maximus verleiht Felix dabei die Ehre eines nicht welkenden Kranzes ${ }^{99}$ (v. 360) und ewige Reichtümer (v. 361) - Gaben, die normalerweise die Märtyrer nach ihrem Tod von Christus im Himmel empfangen. Felix wird also noch zu Lebzeiten und auf der Erde von seinem Bischof wie ein Märtyrer geehrt, obwohl er gar kein Martyrium erlitten hat. ${ }^{100}$ Diese Ehrung gründet sich zunächst auf die Bereitschaft des Felix zum Martyrium und die Qualen, die er während der Haft für seinen Glauben erlitten hat. Der bloße Wille, sich für den Glauben zu opfern und dafür zu leiden, wird dem Märtyrer demnach ebenso hoch angerechnet wie das Martyrium selbst. ${ }^{101}$ Das ist im Falle des Felix auch verständlich, weil sein Martyrium ja allein durch äußere Umstände, nicht etwa durch eigene Feigheit verhindert worden war. Da Maximus aber wohl keine oder bloß unzureichende Kenntnis von den Heldentaten und dem Enthusiasmus des Felix in seiner Märtyrer-Rolle besitzt, muss es für die Ehrung noch einen weiteren Anlass geben, den Maximus selbst miterlebt hat. Ein solcher Anlass kann folglich nur die Hilfe sein, die Maximus von Felix erfahren durfte, und das ist insofern plausibel, als Felix gerade dafür sein eigenes Lebensziel, das Martyrium, aufgeben musste. Die Aufopferung für Maximus besitzt somit denselben (Stellen-)Wert wie der Märtyrertod, das hingebungsvolle Engagement für die Mitmenschen wiegt die Hingabe des eigenen Lebens für den Glauben auf. Wie bereits bei Maximus wird damit eine bestimmte christliche Lebensform und Verhaltensweise, hier der Dienst am Nächsten, als eine weitere Form von und Alternative zum Martyrium anerkannt und gewürdigt. Diese Art von Martyrium ist

98 Ähnlich Kirsch (1985) 110, der betont, dass Paulinus „das Empfinden der Geborgenheit im Heiligen" und die menschliche Nähe des Heiligen vermitteln wollte.

99 Zum Kranz vgl. Sciajno (2008) 326 zu v. 360.

100 So auch Luongo (1992) 93f. mit dem Hinweis, dass Felix verschiedene Ideale realisiere, ohne die jeweilige Rolle wirklich innezuhaben. Er nennt zusätzlich zur Märtyrerehrung ohne Martyrium noch die Gemeindeleitung ohne Bischofsamt sowie die Askese bereits vor der Entstehung des eigentlichen Mönchtums.

101 Ähnlich Kirsch (1983) 333; Luongo (1992) 66; Skeb (1997) 273 und Seng (2006) 484f. Laut Angenendt (1994) 55 erfuhr ein confessor die gleiche Wertschätzung wie ein Märtyrer, „denn auch er hatte seinen Glauben unter Todesdrohung bekannt, ohne aber hingerichtet worden zu sein“; so galt er „als ,martys ex voto‘, als ,Märtyrer dem Willen nach“, und besaß dadurch das volle Verdienst“. 
zwar - anders als die Bereitschaft zum Bekennertod oder die Askese - nicht mit körperlichen Leiden verbunden, bringt aber doch Unannehmlichkeiten und Mühen mit sich, denn sie verlangt von Felix, vom eigenen Weg abzuweichen und sich auf Gottes Plan einzulassen. Und das tut Felix in vorbildlicher Weise: Ohne Groll, Klagen oder ein Zeichen von Enttäuschung fügt er sich in den Willen Gottes und lässt es auch Maximus an keiner Stelle entgelten, dass durch dessen ,Schuld“ sein eigenes Lebensziel gescheitert ist. Wie sein selbstloser Einsatz für Maximus zeigt, geht Felix ganz in seiner neuen Rolle und seinem neuen Betätigungsfeld auf; das Martyrium, dem zuvor sein ganzes Sinnen und Trachten gegolten hatte, ist für ihn irrelevant geworden.

Indem sich Felix vom ,tatsächlichen‘ Märtyrer zum ,Ersatz-Märtyrer‘ entwickelt, macht er eine tiefgreifende Verwandlung durch und das unterscheidet ihn eklatant von den Heiligen, die in anderen Viten gefeiert werden. ${ }^{102}$ Doch diese Entwicklung vollzieht sich erst während der und durch die Hilfe für Maximus. Somit ist es letztlich Maximus selbst, der neues Potential in Felix weckt und dadurch seine Veränderung und Neuausrichtung anstößt, prägt, leitet und ermutigt - zwar unbewusst und unabsichtlich, aber dennoch unübersehbar. Er beeinflusst wesentlich den Charakter und das weitere Handeln des Felix und trägt damit in kaum zu überschätzender Weise zu einer Erweiterung und Modifizierung von dessen bisherigen Heiligenkonzept bei. Daher fungiert Maximus weder als bloße Hintergrundfolie, vor der sich der eigentliche Held Felix abhebt, noch - wie die anderen Figuren in der Felix-Biographie - als vernachlässigbare Randgestalt, die für den Gang der Handlung zwar notwendig ist, aber beim Protagonisten keine Spuren hinterlässt. Maximus ist der Deuteragonist, nach Felix die wichtigste Figur im 4. Natalicium wie auch in der ganzen Felix-Biographie. ${ }^{103}$ Als väterlicher Lehrer und Mentor führt der Bischof aus einer Position scheinbarer Unterlegenheit heraus, ohne aktives Zutun und allein durch seine bloße Existenz einen nicht mehr jungen (!) Priester, überdies einen Heiligen (!), indirekt und unmerklich zu den Konzepten, über die sich später die besondere Heiligkeit des Felix definiert. Eine solche Lehrer-Schüler-Konstellation ist unter den zeitgenössischen Heiligenviten ein Novum und eine einzigartige Besonderheit.

Aufgrund dieser entscheidenden Funktion des Maximus relativiert sich der erste Eindruck, es bestehe eine recht einseitige Beziehung zwischen Felix und Maximus, in der Felix bloß be- und ausgenutzt würde. Felix muss zwar viel investieren, doch er wird dafür auch entschädigt, wenngleich das eher im Hinter-

102 So bemerkt Kirsch (2004) 11, dass in Heiligenbiographien die „Zentralgestalt kaum je eine Entwicklung erfährt, sondern in aller Regel von Anfang an vollkommen ist“.

103 Vgl. Sciajno (2008) 210 zu vv. 198-219: ,... Massimo, vero e proprio deuteragonista di tutta la fabula“. Auch Kirsch (2004) 91 weist Maximus „eine zentrale Rolle“ zu. 
grund geschieht und erst über einen längeren Zeitraum hinweg wirksam wird. Felix unterstützt Maximus bei den kirchlichen Aufgaben in Friedenszeiten (v. 122), aber auch und ganz besonders in der persönlichen Notlage während der Verfolgung; ${ }^{104}$ Maximus liefert dagegen Ansätze zur geistig-spirituellen Neuorientierung und Weiterentwicklung. ${ }^{105}$ Felix bietet also praktisch-reelle Hilfe und profitiert theoretisch-ideell, bei Maximus ist es genau umgekehrt. Damit leisten beide Figuren ihren Beitrag zu und ziehen ihren Nutzen aus dem gegenseitigen Umgang; ihre Interaktion ist folglich durch eine gute Balance zwischen Geben und Nehmen geprägt.

Diese wechselseitige Beziehung und Abhängigkeit zwischen den Protagonisten ist im ganzen Gedicht spürbar. So haben Felix und Maximus zunächst äußere Gemeinsamkeiten: Beide sind Priester, wenngleich mit unterschiedlichem Rang, da Felix presbyte[r] (v. 122), Maximus dagegen episcopus (v. 121) ist; ${ }^{106}$ beide sorgen sich um ihre Gemeinde (vv. 169f. bzw. vv. 202f.); beide müssen ähnliches und gleich schweres Leid ertragen, ${ }^{107}$ das sie im weitesten Sinne selbst verschuldet haben, paradoxerweise durch genau gegensätzliche Aktionen, nämlich durch die Bereitschaft zum Martyrium einerseits bzw. durch die Flucht andererseits; beide beweisen dabei aber Glaubensstärke und sind somit confessores bzw. Märtyrer. Zudem herrscht zwischen Felix und Maximus auch eine große innere Verbundenheit: ${ }^{108}$ Zum einen besteht zwischen ihnen ein so gutes ,Dienstverhältnis‘, dass Maximus in Felix einen Helfer (presbytero Felice potens, v. 122) und sogar den gewünschten Amtserben (sedisque vovebat / heredem, vv. 123f.) sieht; zum anderen sind sie einander auch emotional zugetan, wie die Adjektive car[us] (v. 274, v. 330) und amat[us] (v. 354) belegen. Maximus betrachtet Felix als Teil seiner selbst (pars mea, v. 310; suum, v. 351), während die intensiven Bemühungen des Felix um den sterbenden Bischof wiederum zeigen, dass die Rettung des Maximus für ihn ein persönliches Anliegen und nicht nur eine mechanische Pflichtübung zum Beweis seines Gehorsams gegen Gott darstellt. Diese enge und vertraute Beziehung zwischen Felix und Maximus spiegelt sich in den Begriffen

104 Ebenso Basson (2003) 136.

105 Dies kommt umso überraschender, wenn man wie Basson (2003) 136 von einer spirituellen Unterlegenheit des Maximus gegenüber Felix ausgeht.

106 Maximus wird außerdem als antistes (v. 126; v. 132; v. 220) bezeichnet. Die Begriffe sacerdos (v. 112; v. 230; v. 336) und pastor (v. 169; v. 238) sind dagegen für Felix und Maximus in gleicher Weise verwendet. Eine Untersuchung zur Bedeutung und Verwendung dieser Termini bietet Luongo (1992) 75-80.

107 Dazu ausführlich Basson (2003) 141-145.

108 So auch Evenepoel (1991) 151 und Basson (2003) 136. 
aus dem Wortfeld ,Familie': paren[s] (v. 274), men[s] paterna (v. 122), natu[s] (v. 123, 352), fili[us] (v. 326) und pignus (v. 311).

Die immer wieder betonte familiäre Bindung manifestiert sich am Ende des 4. Natalicium ausführlich und sehr bildhaft in den Folien zweier Vater-Sohn-Paare aus paganer und christlicher Tradition, die das krönende Abschlussgemälde des Gedichts bilden. Felix und Maximus werden damit unter berühmte Vorgänger eingereiht und führen so deren Linie nicht nur fort, sondern bieten - zumindest für die pagane Folie - auch einen gewissen Ersatz.

Die erste Folie illustriert die Rückkehr in die Stadt (vv. 326-337) und ist überdeutlich präsent, obwohl die Vorbilder nicht namentlich genannt werden. Doch wenn Felix den geschwächten Maximus auf die Schultern nimmt (suscipiens humeris, v. 328) und voller pietas (v. 327, v. 333) aus der Wildnis trägt, stehen hier natürlich weniger der gute Hirte und das verirrte Schaf - kurzfristig evoziert durch das Wort ovile (v. 328) - als vielmehr Aeneas und Anchises im Hintergrund. ${ }^{109}$ Felix wird damit zum pius Felix ${ }^{110}$ und zum christlichen Ersatz für den heidnischen pius Aeneas, den er ersetzt und sogar übertrifft, rettet er doch nicht seinen leiblichen, sondern seinen geistlichen Vater.

Die zweite, jetzt ausdrücklich erwähnte Folie ist die alttestamentliche VaterSohn-Beziehung zwischen Isaak und Jakob und illustriert die Segnung des Felix durch Maximus (vv. 354-361). ${ }^{111}$ Maximus ist der Patriarch Isaak (v. 356), Vater (ore paterno, v. 358) und Apostel (ore et apostolico, v. 359) zugleich. Damit verbindet er das Alte und das Neue Testament in seiner Person und fungiert gleich in mehreren Rollen als Stellvertreter des Göttlichen. Felix hingegen wird mit Jakob gleichgesetzt, sodass hier im Stile einer Ringkomposition ein Bogen geschlagen ist zum ersten Teil der Biographie, in dem Felix als Nachfolger des Jakob vorgestellt worden war (vv. 102f.). Die Rolle, die er damals aus eigener Entscheidung und gewissermaßen eigenmächtig übernommen hatte, wird nun durch den Segen des Maximus offiziell bestätigt und legitimiert.

In dieser Schlussszene sind Funktion und Bedeutung der beiden Protagonisten im Vergleich mit den vorherigen Episoden vertauscht bzw. in ihr Gegenteil verkehrt: Maximus ist vom flüchtigen Menschen zum Stellvertreter des Göttlichen, vom schwachen Anchises zum machtvollen Patriarchen und vom Empfänger der munera zum Spender geworden; er übernimmt hier die aktive und

109 Diese Verbindung von paganer und christlicher Folie gibt Sciajno (2008) 304 zu vv. 327-328 sehr treffend wieder mit seiner Bezeichnung des Felix als „pius pastor“, zweifellos eine Kombination aus dem vergilischen pius Aeneas und dem pastor bonus der Evangelien.

110 Ebenso Sciajno (2008) 304 zu vv. 327-328.

111 Sciajno (2008) 319f. zu vv. 350-361 sieht darin eine Übertragung der spirituellen, bischöflichen auctoritas. 
wichtige Rolle. ${ }^{112}$ Felix wiederum ist vom idealen (Märtyrer-)Heiligen zum rangniedrigen Presbyter, vom tapferen Lebensretter und starken Aeneas zum demütig Gesegneten und vom Spender der munera zum Empfänger geworden; damit erweist er sich als die passive und untergeordnete Figur. ${ }^{113}$ Eine solche Rollenverteilung erscheint zwar wie eine abrupte und überraschende Veränderung der bisherigen Situation, entspricht aber eigentlich den üblichen Verhältnissen, die durch die Wirren der Christenverfolgung kurzfristig gestört wurden, und signalisiert so eine Rückkehr zur Normalität.

Mit der Verwendung der beiden Folien am Ende des 4. Natalicium wird ein Rückbezug zu früheren Passagen der Felix-Biographie hergestellt, in denen ebenfalls unterschiedlichste Vorlagen herangezogen worden waren. Doch dort war allein Felix mit Referenzfiguren verglichen worden, sodass nur Einzelpersonen (Jakob, Petrus) bzw. -rollen (Märtyrer) als Folie fungiert hatten. Nun werden sowohl Felix als auch Maximus mit Vorbildern verglichen, aber nicht jeweils für sich genommen, sondern gemeinsam, sodass die Folien ausschließlich Paare (Aeneas und Anchises, Jakob und Isaak) darstellen und damit die enge Verbundenheit der beiden Protagonisten demonstrieren.

Auf diese Weise ist abschließend noch einmal plakativ und symbolhaft in Bilder gefasst, was für das gesamte Gedicht gilt: Felix und Maximus gehören untrennbar zusammen, sie bilden ein Paar, das durch eine innige und auch fruchtbare Beziehung miteinander verbunden ist. Daher sind sie von Anfang an stets mit Blick auf den jeweils anderen konzipiert und definiert und fungieren für ihr Gegenüber als Folie: ${ }^{114}$ Anfangs waren sie scheinbar Kontrastfiguren zur gegenseitigen Abgrenzung, als der mutige Märtyrer dem flüchtigen Bischof gegenübergestellt wurde; mit der Aufwertung des Maximus zum confessor bzw. Märtyrer und der Vermenschlichung des Märtyrers Felix wurden die vorherigen Extreme ausbalanciert und die Figuren zu würdigen Partnern angenähert. Diese Entwicklung erreicht ihren Höhepunkt im Schlussbild, wenn die Protagonisten als Komplementärfiguren auftreten, die sich gegenseitig ergänzen und vervollständigen und nur gemeinsam ein Ganzes bilden: $\mathrm{Zu}$ einer Segnung gehören zwingend und per se ein Segnender und ein Gesegneter.

112 Ähnlich Sciajno (2008) 319f. zu vv. 350-361.

113 Auch Basson (2003) 145 konstatiert einen Wechsel zwischen Aktivität und Passivität sowie zwischen Empfang und Spende von Wohltaten, allerdings allein für Felix und unter anderer Perspektive. Denn er vergleicht, wie sich Felix bei der Befreiung aus dem Gefängnis und dann bei der Rettung des Maximus verhält: In der ersten Szene wird Felix gerettet und empfängt Wohltaten, in der zweiten Szene rettet er selbst und vermittelt Wohltaten.

114 Basson (2003) 135 sieht die Beziehung zu einseitig, wenn er allein Maximus eine solche Funktion als Folie zuschreibt. 


\section{Martyrium oder ,Ersatzmartyrium'/Askese?}

Anhand der beiden Figuren Felix und Maximus werden im Verlauf des 4. Natalicium vier Möglichkeiten christlicher Perfektion vorgestellt: Zunächst das durch Felix vertretene Martyrium, dem dann die von Maximus verkörperte Askese gegenübergestellt wird; mit der Verwandlung des Felix kommen zwei weitere, wenngleich etwas untergeordnete Formen hinzu, nämlich die bloße Bereitschaft zum Martyrium und der Dienst an den Mitmenschen. Diese vier Formen christlicher Vervollkommnung lassen sich zwei verschiedenen Heiligkeits-Idealen zuordnen: Dem ,echten' Martyrium, d.h. dem heiligmäßigen Sterben, einerseits und dem ,Ersatzmartyrium‘, d. h. dem heiligmäßigen Leben, andererseits. ${ }^{115}$

Diese zwei Heiligkeits-Ideale sind völlig konträr und unvereinbar: Wer wie ein Heiliger stirbt, kann nicht zugleich wie ein Heiliger leben. Dieses Problem wird im 4. Natalicium dadurch gelöst, dass die beiden Ideale auf die beiden Protagonisten verteilt werden. Damit sind sie nicht nur zur selben Zeit direkt nebeneinander präsent, sondern es entsteht auch der Eindruck, als seien sie gleich bedeutend und gleichwertig, was durch das ausdrückliche Lob für beide Formen bzw. ihre Träger noch unterstrichen wird. Es scheint folglich so, als würde im 4. Natalicium ein breites und differenziertes Konzept christlicher Perfektion geboten und damit der Tatsache Rechnung getragen, dass es nicht nur den einen Typus ,Christ‘ gibt, sondern viele individuelle Gläubige, die jeweils besondere Stärken und Schwächen und dementsprechend auch ganz individuelle Dispositionen zur Vollkommenheit besitzen. Doch einem solchen Ansatz widerspricht der Ausgang der Erzählung: Das Martyrium wird Felix versagt, während die diversen Formen des ,Ersatzmartyriums‘, besonders die Askese, erfolgreich sind. Sie haben demnach offenbar als die bedeutendere Norm der Heiligkeit zu gelten und sind zur Nachahmung empfohlen.

Das 4. Natalicium bezieht also in der Frage ,Martyrium oder Ersatzmartyrium (Askese)?` eine klare Position, die sich jedoch erst im Verlauf des Gedichtes herauskristallisiert. Dazu wird geschickt die Technik der Leserlenkung eingesetzt, die das Publikum auf einem längeren ,Zickzack-Kurs‘ mit komplexen und wendungsreichen Abschnitten in die Irre lockt, in seinen Erwartungen enttäuscht und zwischen verschiedenen Bewertungen hin- und herführt. Diese Beurteilungen erfolgen dabei wegen der engen Verzahnung der beiden Protagonisten häufig doppelt und von zwei Seiten, d. h. sowohl der Vertreter des einen Ideals als auch

115 Die Martyriumsbereitschaft lässt sich nicht eindeutig einer der beiden Gruppen zuweisen: Denn sie ist zwar durch den Text als ,Ersatzmartyrium` definiert, gehört aber inhaltlich eher dem ,echten' Martyrium an. 
sein ,Gegner‘, der Vertreter des anderen Ideals, konstituieren und stützen durch ihre Handlungen und Erlebnisse das jeweilige Urteil.

Die ersten Partien des zweiten Teils des 4. Natalicium widmen sich nach der fast beiläufigen Erwähnung von Maximus' Flucht (vv. 124f.) dem potentiellen Märtyrer Felix. In 72 Versen (vv. 126-197) bzw. - nach Abzug des Exkurses über die Raserei der Verfolger (vv. 138-163)116 - 46 Versen (vv. 126-137 und vv. 164-197) wird ausführlich und überschwänglich der Märtyrer-Heros Felix gewürdigt. Das Ideal des Martyriums erscheint somit als die einzig gültige und allgemein verbindliche Norm. Doch dann wird ihm mit der positiven Darstellung des Maximus in der Wildnis die Askese als zweite Form bzw. Norm christlicher Bewährung an die Seite gestellt und als ebenbürtig anerkannt: diversa at non leviore ferebat / martyrium cruce (vv. 200f.). Auf der Grundlage dieser Bewertung ist es dann jedoch befremdlich, dass die Passage über Maximus bloß 22 Verse (vv. 198-219) umfasst, also nur etwa halb so viele wie der Abschnitt über Felix, und weniger das heroische Verhalten als vielmehr das Leiden des Protagonisten betont. Damit liegt unweigerlich die Schlussfolgerung nahe, dass die Flucht des Maximus nicht zu billigen ist und die Askese doch keine gleichwertige Alternative zum Martyrium darstellt. Eine solche Annahme wird gestützt durch die Tatsache, dass sich beide Protagonisten zwar in derselben Situation befinden, nämlich in unmittelbarer Todesgefahr, diese Situation aber für die zwei Ideale genau gegensätzliche Konsequenzen hat: Wenn Maximus stirbt, ist mit ihm das Ideal der Askese ausgelöscht; wenn Felix stirbt, ist mit seinem Tod das Ideal des Martyriums erfüllt. Dass die Geschichte unausweichlich ein solches Ende nehmen muss, wird durch die dramatischen Berichte über die Brutalität der Verfolger wie auch den erfolglosen Kampf des Maximus suggeriert. Damit scheinen die Überlegenheit des Martyriums und das Scheitern der Askese endgültig erwiesen zu sein.

Doch dann geschieht eine völlig unvorhersehbare, aus keinem Hinweis erschließbare Wende, in der sich die bisherige Konstellation in ihr Gegenteil verkehrt: Gott beschließt die Rettung des Maximus durch Felix und verhindert so die Auslöschung der Askese wie auch die Erfüllung des Martyriums. Damit ist die Askese zum einen gegen alle möglichen Zweifel als vollgültige Norm der Heiligkeit anerkannt; zum anderen geht sie aus dem Vergleich mit dem Martyrium als nicht nur gleichwertige, sondern sogar überlegene Form christlicher Perfektion hervor. Denn schließlich erfordert die Bewahrung des Askese-Ideals in der Person des Maximus die Aufgabe des Märtyrer-Ideals durch Felix: Felix darf nicht ster-

116 Laut Basson (2003) 141 dient diese Passage über das irrationale Wüten der Verfolger dazu, die Menschen machtlos erscheinen zu lassen, sodass das Verhalten des Felix noch übermenschlicher wirke. 
ben, weil Maximus leben soll; ${ }^{117}$ das eine Ideal muss scheitern, damit das andere erfüllt werden kann. Die Protagonisten und die von ihnen verkörperten Ideale, die zuvor unverbunden und scheinbar gleichberechtigt nebeneinander gestanden hatten, sind nun eng miteinander gekoppelt und direkt voneinander abhängig. Die Askese nimmt dabei offensichtlich die Vorrangstellung ein, denn ihre Ausübung zieht unweigerlich die Vernachlässigung und Ablehnung des Martyriums nach sich. Und so ist auch verständlich, warum Maximus ausgerechnet durch Felix gerettet werden muss - ein Detail, das auf den ersten Blick die Handlung unnötig verkompliziert. ${ }^{118}$ Schließlich wäre es einfacher gewesen, den Engel direkt zu Maximus zu schicken, anstatt Felix aus dem Kerker zu befreien, damit er dann wiederum Maximus retten kann. Doch allein dieser umständliche ,Umweg“, bei dem die Rettung des Märtyrers bloß die Voraussetzung und das Mittel für die Rettung des Asketen darstellt, kann die enge Verknüpfung der beiden Ideale sowie die Bedeutung der Askese und die Zurückstellung des Martyriums illustrieren.

Am Ende des Gedichts werden mit der Segnung weitere Spielarten von ,Ersatzmartyrium' göttlich sanktioniert, nun zwar nicht mehr durch Gott selbst so wie bei der Rettung des Asketen Maximus, aber immerhin durch den Vergleich mit großen Referenzfiguren aus dem Alten und dem Neuen Testament. Wenn Felix und Maximus unter diese Vorbilder der christlichen Heilsgeschichte eingereiht, ja sogar mit ihnen identifiziert werden können, dann sind auch ihre Handlungen mit den besonderen Verdiensten von Patriarchen oder Aposteln vergleichbar und somit vor Gott gerechtfertigt. Da die Handlungen von Felix und Maximus aber ein ,Ersatzmartyrium“ sind, heißt das wiederum, dass auch eine solche symbolische Erfüllung des Martyriums ein besonderes Verdienst und eine vollgültige Form christlicher Bewährung und Vollkommenheit darstellt. Und mit der Märtyrerehrung des Felix ist zu guter Letzt das ,Ersatzmartyrium“ sogar zu einem gleichwertigen Ersatz für das ,echte‘ Martyrium erhoben. Denn hier wird das Urteil, das bei der Einleitung der Maximus-Episode prägnant, aber nur knapp und rein verbal ausschließlich über die Askese gefällt worden war (vv. 200f.), plastisch und einprägsam in ein sinnfälliges Bild gefasst und auch für weitere Formen des symbolischen Martyriums gültig gemacht. Damit sind Felix und Maximus auf

117 Nur verkürzt bei Basson (2003) 145. Wie Cyprian (Pont. vita Cypr. 7-8) und Antonius (Ath. v. Anton. 46, 6) wird Felix zum Nutzen seiner Mitmenschen bewahrt. Hosters (1963) 42 Feststellung zur Vita Cypriani, dass „das Martyrium vor dem Leben, dem Wirken in der Welt zurücktreten“ müsse, gilt demnach auch für Felix.

118 Möglicherweise gehörte diese Episode traditionell zur Felix-Geschichte und konnte daher nicht geändert oder gestrichen werden. Doch damit ist noch nicht die große Bedeutung erklärt, die dieser Passage zugemessen wird. 
verschiedenen Wegen an dasselbe Ziel gelangt: Beide gelten gleichermaßen als Märtyrer, da sie unterschiedliche Formen eines ,Ersatzmartyriums‘ vollzogen haben.

Die letzte Szene des 4. Natalicium vereinigt demnach die vorher stets getrennten oder kontrastierten beiden Ideale von Heiligkeit, d. h. Martyrium und ,Ersatzmartyrium', zu einem gemeinsamen Schlusstableau. Eine solche Verbindung von zwei entgegengesetzten Polen ist aber nur dann möglich, wenn die tiefe Kluft zwischen ihnen auf irgendeine Weise überbrückt werden kann. Das geschieht dadurch, dass jedem Ideal eine bestimmte Funktion und ein eigener Stellenwert zugewiesen werden: Das ,Ersatzmartyrium‘ ist dasjenige Ideal, das im christlichen Alltag wirklich gelebt und praktiziert werden soll, so wie Maximus es vorführt; das Martyrium dagegen ist, wie die symbolische Märtyrerehrung des Felix verdeutlicht, die sinnbildliche Bewertungskategorie und Richtschnur, an der die anderen Formen christlicher Vervollkommnung gemessen werden (müssen).

Mit einem solchen Blick auf die beiden Ideale christlicher Perfektion zollt das 4. Natalicium den religiösen und soziokulturellen Strömungen seiner Zeit bzw. der jüngsten Vergangenheit seinen Tribut. Denn mit der Anerkennung des Christentums und dem Ende der Verfolgungen gingen die Notwendigkeit und/oder die Möglichkeit verloren, den Märtyrertod zu sterben, sodass ein Martyrium kein praktikables Mittel zur spirituellen Bewährung mehr darstellte. Neue Formen der Vervollkommnung, z.B. die Askese, kamen auf, ließen sich aber nicht ohne Weiteres als neue Norm der Heiligkeit und Ersatz für das Martyrium etablieren. ${ }^{119}$ Denn das Martyrium galt weiterhin als das höchste christliche Verdienst, das dem Märtyrer größte Wertschätzung, eine herausragende Position bei Gott und ganz besondere Interzessionskräfte verlieh. ${ }^{120}$ Damit bestand eine erhebliche Diskrepanz zwischen der ihm zugeschriebenen und der tatsächlichen Bedeutung des Martyriums: Während es nach kirchlicher Lehre weiterhin das oberste Ideal und die entscheidende, vielleicht sogar die einzige Norm der Heiligkeit darstellte, war es im christlichen Alltag durch andere Ideale verdrängt worden. ${ }^{121}$ Dieser Konflikt zwischen Theorie und Praxis, zwischen Vergangenheit und Gegenwart wurde, wie sich in der Felix-Biographie besonders klar zeigt, durch einen geschickten Kunstgriff gelöst, indem die neuen Formen christlicher Perfektion mit dem Martyrium verglichen, gleichgesetzt und/oder durch es definiert wurden. Dabei blieb der althergebrachte Begriff ,martyrium‘ erhalten, wurde aber seiner ursprüng-

119 Zum Umbruch des Heiligenideals vgl. Kirsch (1983) 333 und Luongo (1992) 32.

120 Vgl. Brown (1982) 5f.; Rapp (2005) 85-90; 100; Seng (2006) 488.

121 So stellt Hoster (1963) 42 fest, dass das Martyrium zwar nicht seine Wertschätzung, wohl aber seine absolute Stellung verliere und damit zu einem einzelnen, wenngleich bedeutungsvollen Glied einer Kette werde. 
lichen Bedeutung entkleidet, symbolisch verstanden und/oder mit neuem Inhalt gefüllt. Das Wort ,Martyrium‘ war demnach nicht mehr zwingend gleichbedeutend mit dem Bekennertod, sondern bezeichnete nun alle Arten von Zeugnis und Aufopferung für den Glauben, seien es Haft und Folter in Verfolgungszeiten was bisher der Terminus confessio abgedeckt hatte $-{ }^{122}$ oder bestimmte Lebensformen im Alltag, wie z. B. die Askese, die als tägliches, spirituelles oder unblutiges Martyrium ${ }^{123}$ gefeiert wurde. Märtyrer zu sein bzw. zu werden, hieß somit in der Zeit des Paulinus nicht mehr den qualvollen Märtyrertod sterben zu müssen; es genügte, sich in der Welt und im Diesseits durch vorbildliche Eigenschaften und Tätigkeiten verschiedenster Art zu bewähren.

Eine solche Neuinterpretation des Martyriums war zwar (theologisch) nicht unproblematisch, verlieh aber dem Ideal der Heiligkeit neue Impulse und neue Attraktivität: Denn zum einen ließ sich damit das altehrwürdige Märtyrertum mit seinem herausragenden Stellenwert für die ,moderne‘ Zeit retten und fruchtbar machten; zum anderen konnte so die in der Praxis immer stärker um sich greifende Heiligenverehrung von Nicht-Märtyrern auch theoretisch untermauert und legitimiert werden. Wenn nämlich die Nicht-Märtyrer in die unmittelbare Nachfolge der Märtyrer gestellt wurden, deren Heiligkeit bereits sanktioniert war, durften in der Folge auch sie selbst die Privilegien der Märtyrer, d.h. den herausgehobenen Status und die besondere Interzessionskraft, für sich in Anspruch nehmen und wurden auf diese Weise enorm aufgewertet. ${ }^{124}$ Indem jetzt die Nicht-Märtyrer die Tradition der Märtyrer fortführten, entstand eine ununterbrochene Linie von Heiligen bzw. von Heiligkeit vom Tod der Apostel bis in die Gegenwart hinein. Heilige waren also nicht nur die Apostel und Märtyrer der Vergangenheit, sondern auch die Asketen (Eremiten, Mönche) und Kleriker (Priester, Bischöfe) der Gegenwart. Heiligkeit gab es folglich überall und zu jeder Zeit, sie konnte auf unterschiedlichen Wegen erworben werden und war in unterschiedlichen Formen sichtbar.

Dieses ,moderne، Konzept von Heiligkeit spiegelt sich in der christlichen Literatur, und zwar in der neuen literarischen Gattung der Heiligenviten. ${ }^{125}$ Die Heiligenbiographien sind somit eine Antwort auf, zugleich aber auch ein Anstoß

122 Luongo (1992) 64-69 und Sciajno (2008) 212 zu v. 201 verweisen darauf, dass sich schon vor Paulinus die Unterschiede zwischen den Begriffen martyr und confessor verwischt hätten.

123 Vgl. Hoster (1963) 49; Luongo (1992) 39-42; Angenendt (1994) 55; Skeb (1997) 273, der von „,Verinnerlichung“ des Martyriums“ und „,vergeistigende[m]‘ Übergang“ spricht; Baumeister (2009) 215; $244 \mathrm{f}$.

124 Vgl. Luongo (1992) 69. Dass diese Aufwertung durchaus im Interesse der Biographen lag, die jeweils ,ihren' Heiligen gegenüber der großen Konkurrenz besonders verherrlichen wollten, zeigt Seng (2006) 487.

125 Laut Kirsch (2004) 26 ist die Entstehung der Heiligenviten das Resultat einer Anpassung der Literatur an die veränderten Gegebenheiten: Während sich der Bericht über einen Märtyrer auf 
für die geistig-spirituellen Veränderungen: Denn die Biographien greifen die zeitgenössischen Diskurse über Heilige, Heiligkeit und Heiligenverehrung auf und wirken wieder auf sie ein, indem sie diese Themen modellieren, kommentieren und kommunizieren. In dieser Wechselbeziehung konnten die Biographen die öffentliche Meinung beeinflussen und mitgestalten, aber auch die spirituellen Interessen und Bedürfnisse der Gläubigen befriedigen, wie die rasche Entstehung und der überwältigende Erfolg ${ }^{126}$ der Heiligenviten innerhalb einer kurzen Zeitspanne beweisen.

$\mathrm{Zu}$ dieser Gruppe von hagiographischen Schriften, die das neue Heiligenideal der Askese bzw. des ,Ersatzmartyriums“ propagieren, gehört auch die Felix-Biographie, doch dank ihrer Konzeption als Fortsetzungsgeschichte und ihrer eigentümlichen Figurenkonstellation kann sie dieses moderne Konzept auf ganz besondere Art und Weise präsentieren.

So fällt zunächst auf, dass sich die Felix-Biographie im Gegensatz zu den zeitgenössischen Mönchsviten nicht darauf beschränkt, bloß das moderne Heiligenideal, d. h. die Askese oder eine andere Form von ,Ersatzmartyrium‘, zu feiern, sondern die langsame Entstehung und Entwicklung dieses Konzepts schildert. Sie zeigt das alte und das neue Ideal, d.h. Martyrium und ,Ersatzmartyrium', in direktem Kontakt und Zusammenhang, weist beiden aber wechselnde Funktion und Gewichtung zu und bildet so den allmählichen Übergang ${ }^{127}$ vom alten zum neuen Ideal in seinen einzelnen Schritten ab. Damit ist die Felix-Biographie eine Erzählung über den Wandel der Konzepte und Normen von Heiligkeit, der einen Wandel der Hauptfigur Felix nach sich zieht: Die Zeiten ändern sich und deshalb müssen auch die Menschen ihre Vorstellungen und ihr Verhalten ändern und sich an die neuen Gegebenheiten anpassen. Ein solcher Entwicklungsprozess, der sich über einen längeren Zeitraum erstreckt, kann in der Felix-Biographie besonders gut nachgezeichnet werden. Denn der einjährige Abstand zwischen der Veröffentlichung des 4. und des 5. Natalicium unterstützt die Fiktion, dass mittlerweile geraume Zeit verstrichen ist, und verleiht damit der charakterlichen Veränderung des Felix größere Plausibilität, als wenn sie sich innerhalb eines einzigen Gedichts vollzöge.

Dieser allmähliche Übergang vom Märtyrer-Ideal zum ,Ersatzmartyrium“ wird von den beiden Natalicia in seinem gesamten Verlauf nachvollzogen. Das 4.

sein Ende, d.h. seine passio, beschränken könne, müsse die Darstellung eines Asketen sein gesamtes Leben, d. h. seine vita, umfassen.

126 Nach Luongo (1992) 32-34 waren Heiligen-Biographien am Ende des 4. Jahrhunderts regelrechte Bestseller.

127 Luongo (1992) 90 spricht hier zu Recht von „trasposizione monastica del modello di santità martiriale“ und „monachizzazione del martire“. 
Natalicium markiert den Ausgangspunkt, gewissermaßen das ,Vorher', indem es zuerst das Märtyrer-Ideal beschreibt. Mit der Vorstellung der Askese wird dann jedoch bereits die Umbruchs- und Übergangszeit zwischen Martyrium und Askese eingeleitet: Beide Ideale sind nebeneinander präsent, aber auf zwei gleich wichtige Protagonisten verteilt, sodass weder das eine noch das andere für sich genommen die Handlung dominieren kann: Das Märtyrer-Ideal ist nicht mehr, das AskeseIdeal noch nicht so populär, denn die Zeit der Verfolgung neigt sich dem Ende zu, die Askese hingegen steht noch in ihren Anfängen. Das 4. Natalicium schildert die Zeit des ,Nicht-mehr' und des ,Noch-nicht‘ und kündigt damit einen Wandel an, der sich gleichsam in der Zeit ,zwischen“ dem 4. und dem 5. Natalicium vollzieht, denn im 5. Natalicium hat die Entwicklung ihren Endpunkt erreicht und ist abgeschlossen: Das Askese-Ideal hat sich nun fest etabliert, das Märtyrer-Ideal dagegen seine praktische Relevanz für den Alltag völlig verloren. Das wird am Verhalten des Felix überdeutlich, der in der zweiten Verfolgung mehrfach Gelegenheiten zum Martyrium ungenützt verstreichen lässt oder gar dezidiert vermeidet. ${ }^{128} \mathrm{An}$ statt sich wie zuvor als Märtyrer zu exponieren und zu gerieren, ergreift er die Flucht und lebt als Asket in der Einöde. Dieses Handeln wird dadurch legitimiert, dass Felix durch mehrere Wunder vor seinen Verfolgern bewahrt wird und überdies noch in einer besonderen Nähe zu Gott steht (carm. 16,192-214). Felix hat demnach das Beispiel, das Maximus ihm geboten hatte, aufgegriffen und zur Vollendung geführt. Damit ist der Bischof im Nachhinein erneut gerechtfertigt und außerdem erhöht, weil er eine Alternative zum Märtyrer-Ideal ,erfunden' und vorgelebt hat und auf diese Weise sogar für einen Heiligen zum Vorbild geworden ist. Weiterhin wird Felix gewissermaßen zu einer Personifikation der religiöskulturellen Entwicklung, denn während im 4. Natalicium die beiden Ideale ,Martyrium‘ und ,Askese“ noch auf zwei Figuren verteilt waren, sind sie mit dem 5. Natalicium ins Innere der Figur verlegt. Felix vollzieht in seinem Charakter den Übergang vom Märtyrer- zum Askese-Ideal nach und durchläuft im Zeitraffer die Heiligen-Ideale, die vor und während der Zeit des Paulinus prominent waren: Märtyrer (carm. 15,114-197), Eremit (carm. 16,149-214), ${ }^{129}$ beinahe Mönchsbischof (vv. 229-239) und letztlich Asket in der Stadt (vv. 284-296). Damit fungiert Felix als Scharnierfigur zwischen dem ,alten“ Martyrium und dem ,modernen“ ,Ersatzmarty-

128 Er belügt seine Verfolger (carm. 16,72), flieht aus der Stadt und versteckt sich in der Ruine (vv. 82-90), wechselt in der Nacht das Versteck (vv. 149-151) und hält sich sechs Monate (v. 192) lang in der Zisterne verborgen.

129 Diese Verwandlung wird bei Evenepoel (1991) 151 nur beiläufig und ohne jede Erklärung konstatiert: „The honorand [Felix, d. Verf.] is in the first instance a confessor, but he also was, or rather became, an ascetic ...“. 
rium' in seinen diversen Ausprägungen, als Bindeglied zwischen Vergangenheit und Zukunft.

Erstaunlicherweise ist die Handlung des 4. Natalicium aber nicht in der Zeit angesiedelt, in der diese Wende vom Martyrium zum ,Ersatzmartyrium tatsächlich stattfindet, also zu Lebzeiten des Dichters und knapp davor, sondern in der entfernteren Vergangenheit, d.h. in der Zeit der Christenverfolgungen. Gegenwart, Vergangenheit und Zukunft sowie Realität und Fiktion sind dabei in einem geschickten Spiel eng miteinander verknüpft: Paulinus erklärt das Heiligenkonzept seiner realen Gegenwart (Vorrang des Askese-Ideals ${ }^{130}$ ) durch einen Rückblick auf eine nicht genau bestimmte und bestimmbare Vergangenheit, in der die fiktive Erzählung über Felix und Maximus spielt (4. Natalicium); die fiktiven Ereignisse in dieser unbestimmten Vergangenheit sind wiederum die Vorstufe zu einer realen Entwicklung (Ablösung des Märtyrer-Ideals durch das Askese-Ideal); diese reale Entwicklung findet in einer Zeit statt, die sich auf dem Zahlenstrahl gleichsam ,zwischen' der Zeit, in der die Protagonisten angesiedelt sind, und der Zeit, in der Paulinus lebt, befindet; damit liegt sie vom Dichter aus betrachtet bereits in der Vergangenheit, von den Figuren der Erzählung aus gesehen jedoch erst in der Zukunft. Ein Urteil über die Protagonisten und das von ihnen vertretene Ideal ist damit abhängig von der Zeit, in der es getroffen wird: Innerhalb der Erzählung geht Felix somit konform mit den typischen Maximen seiner Epoche und ist eher konservativ, Maximus erscheint dagegen revolutionär und seiner Zeit weit voraus; aus der Perspektive des Publikums hingegen wirkt das Handeln des Felix antiquiert und überholt, das des Maximus zeitgemäß. Dass die progressive Richtung gerade durch den älteren der beiden Protagonisten verkörpert wird, wirkt zunächst befremdlich, ist aber letztlich der Lehrerrolle geschuldet, die Maximus gegenüber Felix implizit einnimmt.

\section{Felix von Nola - ein ,moderner' Heiliger nach dem Konzept des Paulinus}

Altes und Neues, Konformität und Originalität, Konstanz und Wandel, Schein und Sein - das sind die Elemente, die in einer schillernden Mischung das gesamte 4. Natalicium durchziehen. Die Protagonisten und ihre Beziehung zueinander, die Ideale und ihre Bewertung, die Zeit und ihr jeweiliges Heiligenkonzept - alles

130 Zur Bedeutung von Askese und Mönchtum in der Zeit des Paulinus vgl. Lienhard (1977) und Jenal (1995). 
vereint ,moderne“ und alte Vorstellungen, alles ist an unterschiedliche Vorbilder angeglichen und dabei trotzdem erstaunlich unkonventionell, alles wirkt unverrückbar und ist doch im Umbruch begriffen, und alles ist am Ende ganz anders, als es anfangs schien. Das 4. Natalicium ist folglich ein (Ver-)Wandlungsgedicht, in dem Wechsel und Veränderung die größten Konstanten darstellen; und es ist ein Überraschungsgedicht, das mit seinen plötzlichen Wendungen das Publikum in seinen Bann zieht und in Atem hält, aber mit seiner komplexen Struktur auch volle Aufmerksamkeit erfordert.

An dieser Stelle mag man sich nun fragen: Warum eine so vielschichtige und aufwendige Darstellung, wenn es letzten Endes doch bloß darum geht, ein bestimmtes Heiligenkonzept für Felix zu präsentieren? Besteht hier nicht die Gefahr, dass der eigentliche Inhalt von den formalen Raffinessen und Kunstgriffen erdrückt oder verschleiert und damit das Gedicht in seinem Kern missverstanden, im schlimmsten Fall sogar überhaupt nicht verstanden wird? Wäre es nicht einfacher und sicherer gewesen, eine erzähltechnisch weniger anspruchsvolle Form zu wählen, aus der sich leichter und schneller herauskristallisiert, dass Felix als ein menschlicher, asketischer Heiliger konzipiert ist?

Gerade dieses Konzept von Menschlichkeit und Askese ist es jedoch, das eine so komplexe Darstellung erfordert, denn hier werden Züge in die Figur des Felix implementiert, die in dieser Form in seinem bisherigen Profil nicht enthalten waren. Zwar ist die vor Paulinus existierende Felix-Tradition kaum mehr zu greifen, doch wenn die vorhandenen Zeugnisse ${ }^{131}$ den Heiligen als Märtyrer, Schützer bei Verleumdungen und Enthüller der Wahrheit feiern, so sind das völlig andere Schwerpunkte als in der Felix-Biographie und den Natalicia. Paulinus hat also das bestehende Heiligenprofil geändert, umgedeutet und erweitert, ${ }^{132}$ und obgleich sich diese Umarbeitungen nicht vom historischen Kern trennen lassen, ${ }^{133}$ sind doch manche Passagen in der Felix-Biographie als zeitgenössische Einschübe oder (Um-)Akzentuierungen zu erkennen, da sie enge Bezüge zur Epoche und zum Leben des Paulinus aufweisen.

So finden sich in der Felix-Biographie mehrere Anachronismen, die dadurch entstehen, dass gesellschaftliche und/oder kirchliche Diskurse aus der Epoche des Paulinus in die Epoche des Felix rückprojiziert und damit für eine Zeit geltend gemacht werden, in der sie noch gar nicht relevant waren. Das gilt in erster Linie für das Ideal eines asketischen Lebens, ${ }^{134}$ dann aber auch für die kanonische

131 Vgl. dazu Luongo (1992) 46-49 über die Martyrologia und Calendaria, das Damasus-Epigramm sowie die Zeugnisse bei Augustinus.

132 So auch Walsh (1975) 9; Prete (1983) 151; 157 f.; Evenepoel (1991) 144; Kirsch (2004) 77 f.

133 Vgl. Luongo (1992) 18-21.

134 Vgl. auch Luongo (1992) 90 über die „conversatio monastica“. 
Regelung der kirchlichen Ämterabfolge ${ }^{135}$ und die Interzessionskraft und Wirkmacht der Heiligen. Die Felix-Biographie ist damit weniger ein authentisches Zeugnis über die Zeit des Felix als vielmehr ein Spiegelbild ihrer Abfassungszeit ${ }^{136}$ und ein Konstrukt ${ }^{137}$ aus der Feder des Paulinus. In der Folge ist auch Felix nicht so sehr der ,historische‘ Felix von Nola, sondern vielmehr ein Geschöpf des Dichters.

Das wird noch unterstrichen durch die vielen und sehr auffälligen Paralle$\operatorname{len}^{138}$ zwischen der Felix-Biographie und der persönlichen Lebensgeschichte des Paulinus. ${ }^{139}$ Ob und in welchem Ausmaß nun Paulinus sein Leben an dem ,historischen' Felix ausgerichtet oder umgekehrt den fiktionalen Felix nach seinem Leben modelliert hat, lässt sich nicht feststellen. ${ }^{140}$ Denn es mag durchaus Übereinstimmungen zwischen dem ,historischen' Felix und Paulinus gegeben haben; dass sie jedoch so zahlreich und deutlich gewesen sind, ist eher unwahrscheinlich. Daher ist, auch mit Blick auf die weiteren zeitgenössischen Einfügungen und Umarbeitungen der Felix-Biographie, davon auszugehen, dass Paulinus die Figur wie auch die Biographie des Felix bewusst nach sich selbst gestaltet hat. Felix ist immer ein Stück weit auch Paulinus; sein Leben, sein Handeln, Denken und Fühlen sind zu einem gewissen Teil identisch mit dem des Paulinus. Der Heilige wird damit für Paulinus zum Spiegelbild ${ }^{141}$, zur Identifikationsfigur ${ }^{142}$ und auch

135 Luongo (1992) 84-86 vermutet, dass Paulinus die reguläre Karriere des Felix so stark betont habe, um damit seine eigene Bereitschaft zur Akzeptanz dieser Regeln zu demonstrieren, auch wenn - oder vielleicht gerade weil - seine eigene Ordination in mehrfacher Hinsicht dagegen verstoßen hatte.

136 Vgl. Luongo (1992) 12; 22f.; 26; 63. Historisch korrekte Informationen über einen Heiligen zu liefern, ist jedoch nach Luongo (1992) 49f. und Angenendt (1994) 144 nicht das Ziel einer Heiligenbiographie, da sie nur eine bestimmte Form von Heiligkeit propagieren soll.

137 So auch Kleinschmidt (2013) 201.

138 Z.B. die Übersiedelung nach Nola, der weltlich orientierte Bruder, die finanziellen Verhältnisse und die Aufgabe des Erbes, der Rückzug aus der Welt und die Askese, die vorbildliche Haltung in der stürmischen Zeit der Christenverfolgung bzw. Goten-Invasion (vgl. Aug. civ. 1,10), das niedrige Priesteramt und gleichzeitig der überragende Einfluss. Ähnlich Trout (1999) 167-169; Mratschek (2002) 416f. und Kleinschmidt (2013) $199 \mathrm{f}$.

139 Trout (1999) 167 f. bemerkt zu Recht, dass das Subjekt der Felix-Biographie auf den „auctor“ der Biographie verweise und die Biographie unmerklich in Autobiographie übergehe. Deshalb sei die Biographie, so Trout (1993) 123, ein „,self-fashioning“ biographical text“, der die Lebenswahl des Autors verteidigen, seine öffentliche Identität konstituieren und seinen Anspruch auf Autorität bekräftigen solle (129). Auch Mratschek (2002) 416 und Kleinschmidt (2013) 201 sehen die Felix-Biographie des Paulinus als Instrument zur Selbstdarstellung.

140 Ebenso Luongo (1992) $86 \mathrm{f}$.

141 So auch Prete (1983) 156 und Luongo (1992) bereits im Titel seiner Studie.

142 Ähnlich Brown (1981) 56: Felix sei ,a guardian of Paulinus' identity and, almost, at times, a personification of that identity“. Ausführlich Kleinschmidt (2013) 135-140 und 196-204. 
zum eigenen Selbst ${ }^{143}$. Dass Paulinus damit auch die von Felix ausstrahlende Aura der Autorität und Vorbildlichkeit für sich selbst beansprucht ${ }^{144}$ und auf diese Weise seinen eigenen Einfluss als Veranstalter des Kultes festigt ${ }^{145}$, sei hier lediglich am Rande vermerkt.

Solche ,zeitgenössischen“ Themen und Diskurse aus dem Leben und der Epoche des Paulinus, die nicht in der ursprünglichen Felix-Überlieferung enthalten waren, können in das Profil des Felix integriert werden, jedoch bloß innerhalb eines fest vorgegebenen Rahmens. Denn die bestehende Tradition und das Publikum konstituieren ein Grundgerüst, ${ }^{146}$ in das Neuerungen und Änderungen so eingepasst werden müssen, dass sich keine logischen Brüche oder offenen Widersprüche zu vorhandenen Eckdaten ergeben und am Ende eine harmonische Synthese von traditionellen und innovativen Elementen steht. Am ehesten gelingt das bei kleinen Details, die zwar eine bestimmte Einzelaussage transportieren, für den Gang der Ereignisse aber letztlich keine Rolle spielen und deshalb in der Tradition gar nicht oder nur unpräzise formuliert sein können: So stellt beispielsweise die Herkunft des Felix einen Mosaikstein für seine Charakterisierung dar, trägt aber kaum dazu bei, dass sich sein Leben in der vorgegebenen Richtung entwickelt und er zu genau dem Heiligen wird, der er ist. Große Schwierigkeiten ergeben sich hingegen, wenn die Eingriffe des Bearbeiters massiver sind und/oder diejenigen Elemente betreffen, die für den Lebenslauf bzw. die Konzeption der beschriebenen Person konstitutiv und daher entsprechend fest in der Tradition verankert sind, wie z. B. das Heiligenkonzept. Wenn Felix in der frühen Überlieferung als Märtyrer bzw. confessor erschien, Paulinus dann aber die Askese für Felix in Anschlag bringen wollte, ${ }^{147}$ so war das ein diffiziles Unterfangen: Schließlich konnte der Dichter das Märtyrer-/confessor-Profil des Heiligen nicht einfach unterschlagen, in Abrede stellen oder austauschen, denn einen so eklatanten Verstoß gegen die althergebrachte Tradition hätten die Gläubigen wohl kaum akzeptiert; ebenso wenig

143 Paulinus betrachtet z. B. den Geburtstag des Felix als seinen eigenen (Brown 1981, 57; Kleinschmidt 2013, 196-199). Luongo (1992) 86 konstatiert eine so große spirituelle und poetische Symbiose zwischen Felix und Paulinus, dass er zu dem prägnanten Schluss kommt: „L' 'agiografato' coincide con l'agiografo" (94).

144 Darauf verweist Kleinschmidt (2013) 201: Durch die Angleichung an Felix erstelle Paulinus „eine positive Bewertungsgrundlage für seine eigene Lebenserzählung“ und mache deutlich, „dass auch er die Kriterien erfüllt, um als gottesnah und möglicherweise sogar ,heilig“ angesehen zu werden".

145 Ebenso Kirsch (2004) 139; ähnlich Seng (2006) 487.

146 Dass der bestehende Felix-Kult und das Publikum als „Kontrollinstanzen“ fungieren, betonen auch Evenepoel (1991) 144 und Luongo (1992) $45 \mathrm{f}$.

147 Kirsch (2004) 92 verweist bloß sehr knapp darauf, dass Paulinus den Heiligen zum Asketen stilisieren wolle. 
konnte er ein anderes - und noch dazu so gegensätzliches - Heiligenkonzept wie das der Askese zeitgleich und gleichberechtigt neben das Märtyrer-Konzept stellen, ohne damit die Logik und Kohärenz der Handlung empfindlich zu stören.

In diesem Dilemma bietet das 4. Natalicium eine höchst einfallsreiche Lösung, indem es eine allmähliche Ablösung und Ersetzung des alten Ideals durch das neue entwirft: Das Ideal der Askese bzw. des ,Ersatzmartyriums taucht neben dem des Martyriums auf, gewinnt dann zunehmend an Bedeutung und erhält letztendlich das Übergewicht. Auf diese Weise gelingt es Paulinus, traditionelle und innovative Elemente des Heiligenkonzepts zu einem stimmigen Ganzen zu verbinden und den Charakter wie auch die Biographie des Heiligen schlüssig und bruchlos (weiter) zu entwickeln.

Für diese Entwicklung markiert das 4. Natalicium den Ausgangspunkt, die Weichenstellung sowie die erste und bedeutendste Etappe; hier ist der weitere Weg des Heiligen angelegt und begonnen, in gewissem Sinne auch bereits vorgezeichnet. Am Ende dieses Weges (und damit der Biographie) steht ein asketischer, menschlicher Fürsprecher, der an die Bedürfnisse, Vorlieben und Interessen der ,modernen` Zeit angepasst ist. ${ }^{148}$ Dieses spezielle Profil und die Literatur (die Felix-Biographie im Besonderen und die Natalicia im Allgemeinen), durch die es transportiert wird, erheben Felix - trotz seines vergleichsweise unspektakulären, da nicht von Wundertaten geprägten Lebens! - vom kleinen Lokalpatron zum überregional bekannten und beliebten Heiligen und machen ihn gegenüber seinen vielen Mitheiligen konkurrenzfähig.

\section{Verzeichnis der verwendeten Literatur}

Biblia sacra iuxta vulgatam versionem, recensuit et brevi apparatu critico instruxit $\mathrm{R}$. Weber, editionem quintam emendatam retractatam praeparavit R. Gryson, Stuttgart 2007.

Paolino di Nola, I carmi. Testo latino con introduzione, traduzione italiana, note e indici a cura di A. Ruggiero, 1-2 (Strenae Nolanae 6-7), Napoli 1996 (= Ruggiero 1996).

Paolino di Nola, Il carme 15 (Natalicium IV). Introduzione, traduzione e commento a cura di L. Sciajno (Studi sulla Tardoantichità 1), Pisa u. a. 2008 (= Sciajno 2008).

Paulin de Nole, La vie terrestre de saint Félix. Traduction de Natalicia 4 \& $5=$ carm. XV \& XVI par

D. Bocage-Lefebvre, in: B. Gain/P. Jay/G. Nauroy (Hgg.), Chartae caritatis. Études de patristique et d'antiquité tardive en homage à Yves-Marie Duval (Collection des Études Augustiniennes. Série Antiquité 173), Paris 2004, 263-283.

Paulinus Nolanus, Carmina, Indices et Addenda, ed. G. de Hartel. Editio altera supplementis aucta curante M. Kamptner (CSEL 30), Wien ${ }^{2} 1999$ (= von Hartel/Kamptner ${ }^{2} 1999$ ).

148 Nach Kirsch (1983) 335 und (2004) 92 wird Felix immer wieder als „Heiliger der kleinen Leute“ präsentiert. 
St. Paulinus of Nola, The poems. Translated and annotated by P. G. Walsh (Ancient Christian Writers 40), New York 1975 (= Walsh 1975).

A. Angenendt, Heilige und Reliquien. Die Geschichte ihres Kultes vom frühen Christentum bis zur Gegenwart, München 1994.

A. Basson, „Felix, the Ascetic Hero in Paulinus of Nola’s Carmen 15“, in: A. F. Basson/W. J. Dominik (Hgg.), Literature, Art, History: Studies on Classical Antiquity and Tradition. In Honour of W. J. Henderson, Frankfurt am Main 2003, 133-149.

Th. Baumeister, Martyrium, Hagiographie und Heiligenverehrung im christlichen Altertum (RQA Suppl. 61), Roma 2009.

W. Beinert, „Die Heiligen in der Reflexion der Kirche. Systematisch-theologische Grundlegung“, in: W. Beinert (Hg.), Die Heiligen heute ehren. Eine theologisch-pastorale Handreichung, Freiburg im Breisgau 1983, 13-80.

P. Brown, The Cult of the Saints. Its Rise and Function in Latin Christianity, Chicago 1981.

K. Burkhard, Das antike Geburtstagsgedicht, Zürich 1991 (Diss. Zürich 1985).

J. Desmulliez, „Paulin de Nole. Études chronologiques (393-397)“, RecAug 20, 1985, 35-64.

W. Evenepoel, „The Vita Felicis of Paulinus Nolanus and the Beginnings of Latin Hagiography“, in: A. A. R. Bastiaensen/A. Hilhorst/C. H. Kneepkens (Hgg.), Fructus centesimus. Mélanges offerts à Gerard J. M. Bartelink à l'occasion de son soixante-cinquième anniversaire (Instrumenta Patristica 19), Steenbrugge 1989, 167-176.

W. Evenepoel, „The Vita Felicis of Paulinus Nolanus“, in: M. van Uytfanghe/R. Demeulenaere (Hgg.), Aevum inter utrumque. Mélanges offerts à Gabriel Sanders, professeur émérite à l'Université de Gand (Instrumenta Patristica 23), Steenbrugge 1991, 143-152.

P. Fabre, Essai sur la chronologie de l'œuvre de Saint Paulin de Nole (Publications de la Faculté des Lettres de l'Université de Strasbourg 109), Paris 1948.

P. Fabre, Saint Paulin de Nole et l'amitié chrétienne (Bibliothèque des Écoles Françaises d'Athènes et de Rome 167), Paris 1949.

Chr. Gnilka, „Züge der Mündlichkeit in spätlateinischer Dichtung“, in: G. Vogt-Spira (Hg.), Strukturen der Mündlichkeit in der römischen Literatur (ScriptOralia 19, Reihe A: Altertumswissenschaftliche Reihe 4), Tübingen 1990, 237-255.

R. P. H. Green, The Poetry of Paulinus of Nola. A Study of his Latinity (Collection Latomus Volume 120), Bruxelles 1971.

R. Herzog, „Probleme der heidnisch-christlichen Gattungskontinuität am Beispiel des Paulinus von Nola“, in: A. Cameron/M. Fuhrmann (Hgg.), Christianisme et formes littéraires de l'antiquité tardive en occident. Vandœuvres-Genève, 23-28 août 1976 (Entretiens sur l'antiquité classique 23), Genève 1977, 373-423.

D. Hoster, Die Form der frühesten lateinischen Heiligenviten von der Vita Cypriani bis zur Vita Ambrosii und ihr Heiligenideal, Diss. Köln 1963.

G. Jenal, Italia ascetica atque monastica. Das Asketen- und Mönchtum in Italien von den Anfängen bis zur Zeit der Langobarden (ca. 150/250-604), Bd. 1-2 (Monographien zur Geschichte des Mittelalters 39,1-2), Stuttgart 1995.

H. Junod-Ammerbauer, „Le poète chrétien selon Paulin de Nole. L'adaptation des themes classiques dans les Natalicia“, REAug 21, 1-2, 1975, 13-54.

W. Kirsch, „Die Natalicia des Paulinus von Nola als Mittel ideologischer Beeinflussung“, Klio 65, 2, 1983, 331-336.

W. Kirsch, „Zum Verhältnis von Poetologie und Poetik bei Paulinus von Nola. Paul Klopsch zum 65. Geburtstag“, MLatJb 20, 1985, 103-111. 
W. Kirsch, Laudes sanctorum. Geschichte der hagiographischen Versepik vom IV. bis X. Jahrhundert, I. Ansätze. IV.-VIII. Jahrhundert. Erster Teilband (Quellen und Untersuchungen zur lateinischen Philologie des Mittelalters 14,1,1), Stuttgart 2004.

A. L. Kleinschmidt, Ich-Entwürfe in spätantiker Dichtung. Ausonius, Paulinus von Nola und Paulinus von Pella, Heidelberg 2013.

K. Kohlwes, Christliche Dichtung und stilistische Form bei Paulinus von Nola, Bonn 1979 (Diss. Bonn 1978).

J. T. Lienhard, Paulinus of Nola and Early Western Monasticism. With a Study of the Chronology of His Works and an Annotated Bibliography, 1879-1976 (Theophaneia 28), Köln u. a. 1977.

G. Luongo, Lo specchio dell'agiografo: S. Felice nei carmi XV e XVI di Paolino di Nola (Parva hagiographica 3), Napoli 1992.

E. E. Malone, The monk and the martyr. The monk as the successor of the martyr (The Catholic University of America studies in Christian antiquity 12), Diss. Washington 1950.

S. Mratschek, Der Briefwechsel des Paulinus von Nola. Kommunikation und soziale Kontakte zwischen christlichen Intellektuellen (Hypomnemata 134), Göttingen 2002.

A. V. Nazzaro, „Intertestualità biblica e classica in testi cristiani antichi“, in: B. Amata (Hg.), Cultura e lingue classiche 3. 30 Convegno di aggiornamento e di didattica, Palermo, 29 ottobre-1 novembre 1989, Roma 1993, 489-514.

S. Prete, „Paolino agiografo: Gli atti di S. Felice di Nola (carm. 15-16)“, in: Atti del Convegno. XXXI Cinquantenario della morte di S. Paolino di Nola (431-1981). Nola, 20-21 marzo 1982, Roma 1983, 149-159.

C. Rapp, Holy Bishops in Late Antiquity. The Nature of Christian Leadership in an Age of Transition, Berkeley u. a. 2005.

H. Seng, „Felix sine sanguine martyr: Die Norm der Heiligkeit und ihre symbolische Erfüllung bei Paulinus von Nola, carmen XIV“, Studia Patristica 43 (Papers presented at the Fourteenth International Conference on Patristic Studies held in Oxford 2003), Leuven 2006, 483-489.

M. Skeb, Christo vivere. Studien zum literarischen Christusbild des Paulinus von Nola (Hereditas 11), Bonn 1997 (Diss. Bochum 1995/96).

J. L. Smith, The natalicia of Paulinus of Nola and the embodiment of authority at the Shrine of St. Felix, Ann Arbor MI 2004 (Diss. Bloomington 2004).

D. E. Trout, Secular renunciation and social action: Paulinus of Nola and late Roman society, Ann Arbor MI 1990 (Diss. Durham 1989).

D. E. Trout, „Amicitia, Auctoritas, and Self-Fashioning Texts: Paulinus of Nola and Sulpicius Severus“, Studia Patristica 28 (Papers presented at the Eleventh International Conference on Patristic Studies held in Oxford 1991), Leuven 1993, 123-129.

D. E. Trout, „Town, Countryside, and Christianization at Paulinus’ Nola“, in: R. W. Mathisen/ H. S. Sivan (Hgg.), Shifting Frontiers in Late Antiquity, Aldershot 1996, 175-186.

D. E. Trout, Paulinus of Nola. Life, Letters, and Poems, Berkeley u. a. 1999. 